Cochrane Database of Systematic Reviews

\title{
Ganoderma lucidum mushroom for the treatment of cardiovascular risk factors (Review)
}

Klupp NL, Chang D, Hawke F, Kiat H, Cao H, Grant SJ, Bensoussan A

Klupp NL, Chang D, Hawke F, Kiat H, Cao H, Grant SJ, Bensoussan A.

Ganoderma lucidum mushroom for the treatment of cardiovascular risk factors.

Cochrane Database of Systematic Reviews 2015, Issue 2. Art. No.: CD007259.

DOI: 10.1002/14651858.CD007259.pub2.

www.cochranelibrary.com 
TABLE OF CONTENTS

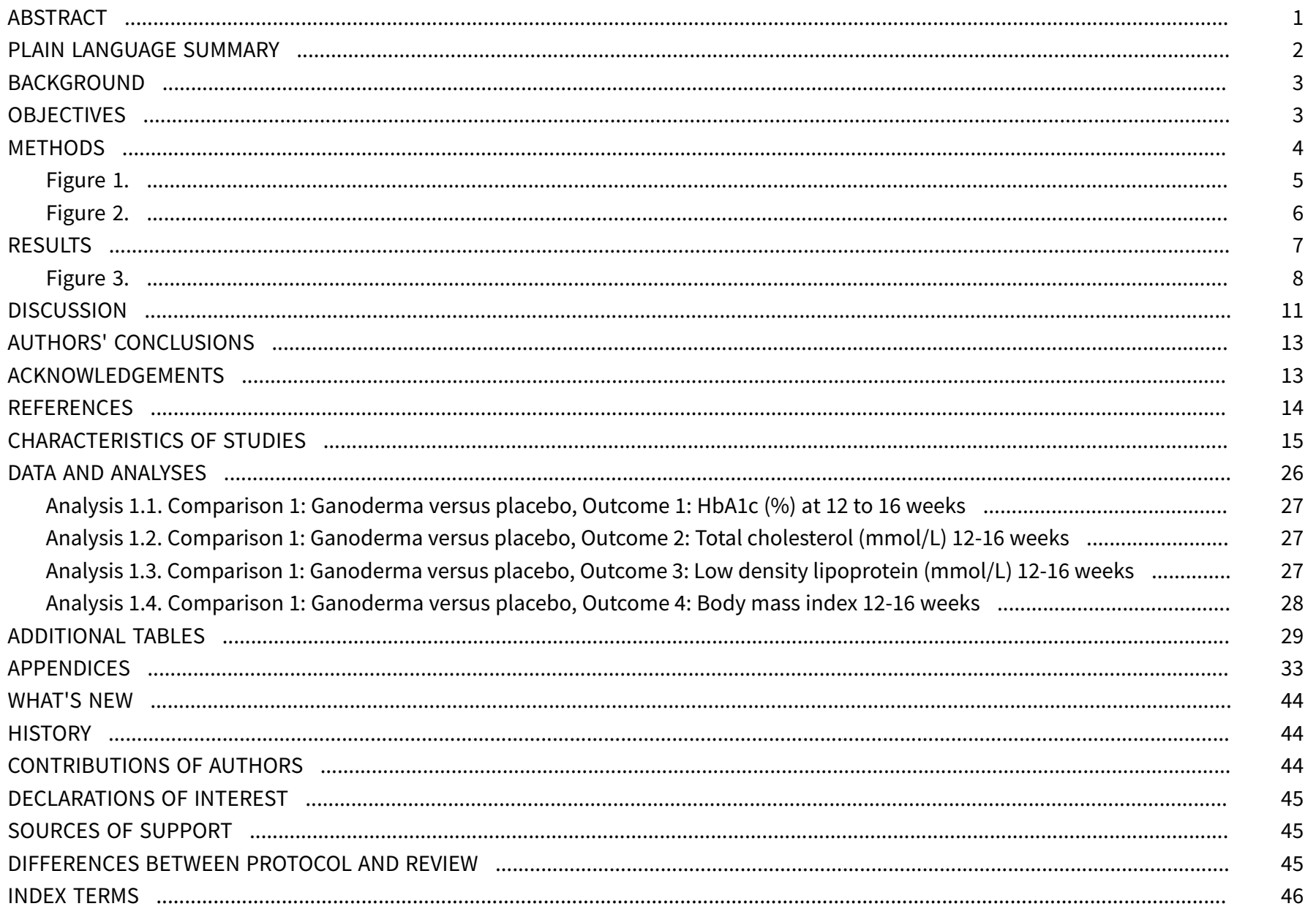


[Intervention Review]

\section{Ganoderma lucidum mushroom for the treatment of cardiovascular risk factors}

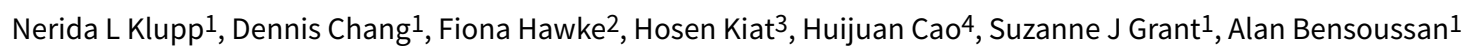

1National Institute of Complementary Medicine, University of Western Sydney, Sydney, Australia. 2School of Health Sciences, Faculty of Health and Medicine, The University of Newcastle, Ourimbah, Australia. ${ }^{3}$ The Australian School of Advanced Medicine, Macquarie University, Cardiac Health Institute, Sydney, Australia. ${ }^{4}$ Centre for Evidence-Based Chinese Medicine, Beijing University of Chinese Medicine, Beijing, China

Contact: Nerida L Klupp, n.klupp@uws.edu.au.

Editorial group: Cochrane Heart Group.

Publication status and date: Stable (no update expected for reasons given in 'What's new'), published in Issue 9, 2021.

Citation: Klupp NL, Chang D, Hawke F, Kiat H, Cao H, Grant SJ, Bensoussan A. Ganoderma lucidum mushroom for the treatment of cardiovascular risk factors. Cochrane Database of Systematic Reviews 2015, Issue 2. Art. No.: CD007259. DOI: 10.1002/14651858.CD007259.pub2.

Copyright ( 2015 The Cochrane Collaboration. Published by John Wiley \& Sons, Ltd.

\section{A B S T R A C T}

\section{Background}

Ganoderma lucidum (also known as lingzhi or reishi) is a mushroom that has been consumed for its broad medicinal properties in Asia for over 2000 years. G lucidum is becoming increasingly popular in western countries as a complementary medicine for cardiovascular health.

\section{Objectives}

To evaluate the effectiveness of $G$ lucidum for the treatment of pharmacologically modifiable risk factors of cardiovascular disease in adults.

\section{Search methods}

We searched the Cochrane Central Register of Controlled Trials (CENTRAL Issue 6 of 12, 2014) on The Cochrane Library, MEDLINE (OVID, 1946 to June week 3 2014), EMBASE (OVID, 1980 to 2014 week 26), Science Direct (1823 to 2013), Current Controlled Trials (1990 to 2013), Australian New Zealand Clinical Trials Registry (2005 to 2013), Chinese Biomedical Literature Database (2007 to 2013), Chinese Medical Current Contents (2007 to 2013) and other databases. We checked reference lists of included studies, contacted content experts and handsearched The International Journal of Medicinal Mushrooms. We applied no language or publication restrictions.

\section{Selection criteria}

Randomised controlled trials and controlled clinical trials of $G$ lucidum for the treatment of cardiovascular risk factors. Primary outcomes were blood glucose level, blood pressure and lipid profile.

\section{Data collection and analysis}

Two authors independently selected trials, assessed risk of bias and cross checked data extraction and analysis. A third author arbitrated in the event of disagreement.

\section{Main results}

Five trials with a total of 398 participants were eligible for inclusion. Of these, one study was published in Chinese and translated to English; one study was published but study authors provided the additional data used in this review; one study was unpublished and the study authors provided data; and two studies did not provide comparison group data suitable for statistical analyses. The three studies from which data were used for statistical analyses compared G lucidum (1.4 g to $3 \mathrm{~g}$ per day) to placebo over 12 to 16 weeks of intervention. 
Although inclusion criteria varied, all participants of these three studies had type 2 diabetes mellitus. Of the five included studies, risk of bias was low for one study and unclear for the remaining four.

Results from two studies showed that $G$ lucidum was not associated with statistically or clinically significant reduction in HbA1c (WMD $-0.10 \% ; 95 \% \mathrm{Cl}-1.05 \%$ to $0.85 \% ; 130$ participants), total cholesterol (WMD $-0.07 \mathrm{mmol} / \mathrm{L} ; 95 \% \mathrm{Cl}-0.57 \mathrm{mmol} / \mathrm{L}$ to $0.42 \mathrm{mmol} / \mathrm{L} ; 107$ participants ), low-density lipoprotein cholesterol (WMD $0.02 \mathrm{mmol} / \mathrm{L} ; 95 \% \mathrm{Cl}-0.41 \mathrm{mmol} / \mathrm{L}$ to $0.45 \mathrm{mmol} / \mathrm{L} ; 107$ participants), or body-mass index (WMD $-0.32 \mathrm{~kg} / \mathrm{m}^{2} ; 95 \% \mathrm{Cl}-2.67 \mathrm{~kg} / \mathrm{m}^{2}$ to $2.03 \mathrm{~kg} / \mathrm{m}^{2} ; 107$ participants). All other analyses were from a single study of 84 participants. We found no improvement for fasting plasma glucose (WMD $0.30 \mathrm{mmol} / \mathrm{L} ; 95 \% \mathrm{Cl}-0.95 \mathrm{mmol} / \mathrm{L}$ to $1.55 \mathrm{mmol} / \mathrm{L}$ ). Measures of post-prandial blood glucose level found inconsistent results, being in favour of placebo for '2-hour post-prandial blood glucose' (WMD 0.7 mmol/L; $95 \%$ $\mathrm{Cl} 0.29 \mathrm{mmol} / \mathrm{L}$ to $1.11 \mathrm{mmol} / \mathrm{L}$ ) and in favour of $\mathrm{G}$ lucidum for 'plasma glucose under the curve at 4th hour' (WMD -49.4mg/dL/h; 95\% $\mathrm{Cl}-77.21 \mathrm{mg} / \mathrm{dL} / \mathrm{h}$ to $-21.59 \mathrm{mg} / \mathrm{dL} / \mathrm{h}$ ). As the Minimal Clinical Important Differences are unknown, the clinical significance of this effect is unclear. There were no statistically significant differences between groups for blood pressure or triglycerides. Participants who took $G$ lucidum for four months were 1.67 times (RR $1.6795 \% \mathrm{Cl} 0.86$ to 3.24) more likely to experience an adverse event than those who took placebo but these were not serious side effects.

\section{Authors' conclusions}

Evidence from a small number of randomised controlled trials does not support the use of $G$ lucidum for treatment of cardiovascular risk factors in people with type 2 diabetes mellitus. Future research into the efficacy of $G$ lucidum should be placebo-controlled and adhere to clinical trial reporting standards.

\section{PLAIN LANGUAGE SUMMARY}

\section{Ganoderma lucidum mushroom (lingzhi/reishi) for treating cardiovascular risk factors}

\section{What are cardiovascular risk factors?}

Cardiovascular disease is the name given to any disease, such as heart attack or stroke, that affects the heart and circulatory system (which moves blood around the body). Risk factors for cardiovascular diseases include high blood pressure, and high levels in the blood of glucose and cholesterol. People with cardiovascular risk factors are more likely to have a heart attack or stroke than people without them.

\section{What is Ganoderma lucidum?}

Ganoderma lucidum (G lucidum), also known as 'lingzhi' or 'reishi', is a mushroom that is commonly used in traditional Chinese medicine. In China, G lucidum is taken in the traditional form of a decoction (mashed and boiled in water), or in tea or coffee. Recently it has been manufactured as an extract in tablets and capsules for the western market, as it is now being used in western countries in the hope that it might improve cardiovascular health.

\section{The purpose of this review}

Researchers from the Cochrane Collaboration tried to determine whether G lucidum, when compared with another medicine or a fake medicine - called a placebo - is an effective treatment for reducing cardiovascular risk factors.

\section{What this review discovered}

The researchers searched the medical literature up to June 2014 to identify all the relevant medical research. They identified a total of 5 medical studies that compared $G$ lucidum with placebo in a total of 398 people with type 2 diabetes. Overall the quality of the studies was poor. Unpublished data was obtained for two of the included studies and one study was translated from Chinese. The daily doses of G lucidum taken varied between trials from $1.4 \mathrm{~g}$ to $5.4 \mathrm{~g}$. In 1 trial participants in the G lucidum group took capsules that contained either G lucidum only, or a mixture of $G$ lucidum ( $75 \%$ of capsule weight) and another fungus called Cordyceps sinensis ( $25 \%$ of capsule weight). Duration of trials varied from 12 to 16 weeks.

Two of the 5 trials reported results for the participants treated with $\mathrm{G}$ lucidum only, but not for those treated with placebo, and so the information from them could not be used. The remaining 3 trials with 157 participants provided information for analysis.

This information showed that $G$ lucidum was not an effective treatment for reducing blood glucose, blood pressure, or cholesterol. It was not clear whether $G$ lucidum might reduce blood glucose after a meal, as the only information for this came from a single study of indeterminable quality.

There was not enough information to determine the overall safety of taking G lucidum. One study showed some increased risk of mild harms in participants who took G lucidum in the form of nausea, diarrhoea or constipation.

Future research in this field should include clinical trials that are better reported. 


\section{B A C K G R O U N D}

\section{Description of the condition}

The social, economic and personal burden of cardiovascular disease is well recognised. The World Health Organisation estimates at least 17 million deaths per year worldwide are due to cardiovascular disease (WHO 2011). This includes coronary heart disease - independently the world's leading cause of death - and stroke. Stroke also has the highest prevalence rates for disability in many countries (WHO 2011). With rates of diabetes and obesity rapidly increasing in both the developed and developing world, it is expected that morbidity and mortality rates for cardiovascular disease will continue to rise (Capewell 2011; Hossain 2007).

Cardiovascular disease is multi-factorial in causation. Over 300 risk factors have been identified as likely contributors to vascular pathogenesis and, in combination, may have complex and cumulative metabolic effects. Tobacco, alcohol, high blood pressure, high cholesterol, high blood glucose and obesity remain the primary modifiable risk factors (Hossain 2007; WHO 2011), and novel markers are being increasingly researched for their predictive ability and role in the development of cardiovascular disease. These include homocysteine, markers of inflammation, such as Creactive protein, and markers of abnormal coagulation, including fibrinogen (Pearson 2003).

\section{Description of the intervention}

Ganoderma lucidum, also known as 'lingzhi' or 'reishi', is a mushroom that has been consumed for its broad medicinal properties in Asia for 2000 years, and has more recently been introduced to western society. As with most herbal interventions, it is regarded as both medicine and food to bring the body 'into balance', promote health, prolong life and prevent and cure many systemic diseases (Willard 1990). The potential of G lucidum to treat multiple primary risk factors for cardiovascular disease safely and effectively has increased interest in this medicinal mushroom. The intervention may still be purchased in the more traditional form of decoction, tea or coffee, but is increasingly manufactured as an extract in tablets and capsules for the western market.

The Ganoderma fungus has a fruiting body (the mushroom, or basidiocarp), a mycelium (the filamentous form) and spores (for reproduction). The active constituents of $G$ lucidum include polysaccharides (including beta-D-glucans, heteropolysaccharides and glycoproteins), triterpenes, germanium, essential and nonessential amino acids, sterols, lipids, anti-oxidants, vitamins B1, B2, B6, iron, calcium, and zinc (Huie 2004; McKenna 2002). Results from clinical trials indicate $G$ lucidum can lower blood pressure, cholesterol, and blood glucose in humans (Gao 2004a; Gao 2004b Jin 1996; Kanmatsuse 1985; Wachtel-Galor 2004a; Wachtel-Galor 2004b). In these trials, no abnormalities in haematological and biochemical (including hepatic and renal) safety biomarkers, and no moderate, serious or severe adverse events were reported for the participants. There is no agreed dosage for $G$ lucidum treatment, however, most recommended amounts vary between $1.5 \mathrm{~g}$ and $9 \mathrm{~g}$ of dried extract per day (Chang 2000; Teow 1996). There are some claims that spores contain higher quantities of the active constituents. This has not been determined by research, and any medicinal benefit is unclear.

\section{How the intervention might work}

Unlike many synthetic medicines, $G$ lucidum's mode of action and guidelines for use are not well established. The Ganoderma mushroom contains pharmacologically active variables and the effects and effectiveness of the whole product are likely to differ from that of a single component acting alone. Data from animal and in vitro studies suggest that the constituents, either individually or synergistically, produce antioxidant, antiinflammatory, antihyperglycaemic, antiatherogenic and immuneprotective beneficial effects (Chen 2004; Lakshmi 2003; Yang 2002; Zhang 2004). As with most herbal medicines, matching single constituents with specific-disease modifying effects is very difficult. For $G$ lucidum, researchers suggest there are two groups of prominent bioactive components that have effects on the cardiovascular system. These are triterpenes and polysaccharides. $G$ lucidum is the only known source of triterpene fatty acids called ganoderic acids. Of the 200 that have been identified, ganoderic acids $A, B$ and $C$ are thought to have hypoglycaemic effects (Hikino 1985; Tomoda 1986), while ganoderic acids F, B, $\mathrm{D}, \mathrm{H}, \mathrm{K}, \mathrm{S}$ and $\mathrm{Y}$ are most likely hypotensive in their action (Morigawa 1986). The probable mode of action of ganoderic acid $B$ (ganoderol) on glycaemia is by inhibition of a-glycosidase that affects carbohydrate digestion (Fatmawati 2011). Ganoderic acids might inhibit many enzymatic activities, including those of angiotensin-converting enzyme (Huie 2004), and might suppress sympathetic efferent activity (Lee 1990). Ganoderic acid S has been identified as an inhibitor of platelet aggregation (Shimizu 1985; Tao 1990). Most ganoderic acids are also thought to be active inhibitors of cholesterol synthesis (Komoda 1989). The second constituent group that might have effects on the cardiovascular system is polysaccharides. Over 150 polysaccharide molecules, including beta-D-glucans, heteropolysaccharides and glycoproteins have been identified in G lucidum (Chang 1999). Evidence suggests these structurally diverse macromolecules also have hypoglycaemic effects (Tomoda 1986; Zhang 2004).

\section{Why it is important to do this review}

Human trials that have evaluated $G$ lucidum vary greatly with regard to the level and quality of evidence, internal and external validity, and in particular, the analysis and reporting of results. This provides a challenge to health professionals to determine effectiveness for cardiovascular risk factor management from an evidencebased perspective. A systematic review of this increasingly popular complementary medicine is required for both eastern and western medical practice. This review will evaluate the effectiveness of G lucidum for the management of pharmacologically modifiable cardiovascular risk factors.

\section{O B JECTIVES}

To evaluate the effectiveness of $G$ lucidum for the treatment of pharmacologically modifiable risk factors of cardiovascular disease in adults. 


\section{METHODS}

\section{Criteria for considering studies for this review \\ Types of studies}

Randomised controlled trials, controlled clinical trials (as defined by Higgins 2011), and randomised cross-over studies, for which only data from the first phase were to be included.

\section{Types of participants}

Any adult identified as having at least one cardiovascular risk factor listed as a primary outcome measure in this review. The cardiovascular risk factor must have been evaluated in the context of prevention or treatment of a cardiovascular-related disease (for example, blood pressure changes evaluated in a cancer trial were excluded)

\section{Types of interventions}

As with most complementary medicines, a range of strains, herb products and active ingredients may be utilised under the same product name. Therefore a degree of heterogeneity was expected. $G$ lucidum is frequently combined with a second ingredient aimed at increasing potency. Trials evaluating a combined formulation were included if there was only one additional ingredient and $G$ lucidum represented at least $75 \%$ of the constituent weight. Co-intervention was allowed as long as all arms of the study received the same cointervention. G lucidum:

- may include teas, decoctions, or powders in any form;

- may be raw or as an extract;

- may include any part of the mushroom;

- may be used at any dose (dosage equivalence between types of intervention is difficult to determine);

- must be taken for longer than 21 days;

- may be used as an isolated active compound e.g. G lucidum polysaccharide extract may be included.

Comparison was against placebo or alternative pharmacological or non-pharmacological treatment.

\section{Types of outcome measures}

\section{Primary outcomes}

One primary outcome measure was required for studies to be included in this systematic review. Primary and secondary outcomes measures needed to be outside normal range at baseline.

- Blood glucose level (for example, fasting blood glucose/ glycosylated haemoglobin ( $\mathrm{HbA1c}$ )/postprandial glucose test).

- Blood pressure (systolic/diastolic/mean blood pressure).

- Lipid profile (total triglycerides, total cholesterol, high density lipoprotein cholesterol, low density lipoprotein cholesterol, very low density lipoprotein cholesterol).

- Prevalence of any of the above.

\section{Secondary outcomes}

- Obesity measures (waist circumference, hip-waist ratio, fat percentage, body weight, body-mass index).
- Insulin (fasting insulin, pro-insulin, homeostasis model assessment (HOMA-IR)).

- Fibrinogen.

- Homocysteine.

- Health-related quality of life.

\section{Adverse events}

- Adverse event symptoms and signs attributable to treatment.

- Evidence of liver dysfunction.

- Evidence of renal dysfunction.

\section{Search methods for identification of studies}

\section{Electronic searches}

The following databases were searched in October 2010 and updated in November 2011 (Appendix 1) Some databases were also searched in April 2013 and June 2014 (Appendix 2).

\section{Health databases}

- The Cochrane Central Register of Controlled Trials (CENTRAL, Issue 6 of 12, 2014) on The Cochrane Library

- MEDLINE via PubMed Entrez (1950 to November 2011) and via OVID (1946 to June week 32014 )

- Science Direct (1823 to 2013)

- EMBASE (OVID, 1980 to 2014 week 26)

- MD Consult (1995 to 2013)

- Stat!Ref-Medical (1998 to 2013)

- Biomed Central (1997 to 2013)

- Scopus (1966 to 2013)

- CINAHL Plus with Full Texts (EBSCO, 1937 to 20 June 2014)

- Current contents (1998 to 2013)

- Health and Medical Complete (1986 to 2013)

- Science Citations Index Expanded (SCl-Expanded) and Conference Proceedings Citation Index - Science (CPCI-S) on Web of Science (Thomson Reuters, 1970 to 27 June 2014)

- BIOSIS on Web of Science (Thomson Reuters, 1969 to 27 June 2014)

\section{Databases of ongoing trials}

- Current Controlled Trials (1990 to 2013)

- Australian New Zealand Clinical Trials Registry (2005 to 2013)

- CenterWatch Clinical Trials Listing Service (USA) (1995 to 2013)

- National Institutes of Health (USA) (1800 to 2013)

- clinicaltrials.gov (National Institutes of Health) (2000 to 2013)

\section{Complementary medicine database}

- Chinese Biomedical Literature Database (CBM) (2007 to 2013)

- Chinese Medical Current Contents (CMCC) (2007 to 2013)

- China Network Knowledge Infrastructure (CNKI) (1979 to 2013)

- VIP Database (1989 to 2013)

We applied no language restrictions. Published or unpublished studies, including those only available as abstracts, were eligible for inclusion.

- Inflammatory markers (C-reactive protein, apolipoprotein). 


\section{Searching other resources}

- We checked reference lists of all included studies for other potentially eligible studies.

- We communicated with authors in the relevant field, medicinal mushroom research centres and relevant pharmaceutical companies (Appendix 3).

- We handsearched the International Journal of Medicinal Mushrooms.

\section{Data collection and analysis}

\section{Selection of studies}

Two authors (NK and $\mathrm{FH}$ ) independently evaluated the English language titles and abstracts, where available. One author ( $\mathrm{HC})$ evaluated Chinese language titles and abstracts. We retrieved full text versions for all potentially relevant studies (NK). Two authors (NK and $\mathrm{HC}$ ) independently evaluated full text versions for eligibility. Authorship and results were not blinded, as the effectiveness of applying this process has not been established by empirical evidence (Higgins 2011). We resolved any disagreement by discussion between authors. We did not need a third author (SG) to arbitrate for a disagreement.

\section{Data extraction and management}

Two authors (FH and $\mathrm{HC}$ ) independently extracted data using a pilot-tested data extraction form. One author (NK) checked data extraction forms for agreement. No arbitration of disagreement was needed. The following data were extracted:

- general information: title, authors, contact details, country, sponsor;

- verification of inclusion criteria that were met;

- publication details: published or unpublished, abstract only or not, publication type, language, standard referencing details, duplicate publications;
- trial characteristics: design (parallel or cross-over), recruitment procedures, method of randomisation, allocation concealment, blinding (participants, intervention administrators, outcome assessors), evaluation of blinding by trialists, setting, quality appraisal;

- participants: inclusion and exclusion criteria, total number and numbers in comparison groups, baseline characteristics;

- interventions: the composition or ingredients; preparation method, dose, route, and duration of intervention; comparison intervention; co-intervention; and expertise of practitioner;

- outcomes: outcomes specified above and adverse events;

- follow-up: length of follow-up, reason and number of dropouts and withdrawals, compliance, and intention-to-treat analysis.

\section{Assessment of risk of bias in included studies}

Risk of bias of included trials was rated independently by two authors ( $\mathrm{HC}$ and $\mathrm{FH}$ ) using the following criteria, as described in the Cochrane Handbook of Systematic Reviews of Interventions (Higgins 2011). Disagreements were arbitrated by a third author (NK).

- sequence generation;

- concealment of allocation;

- blinding;

- incomplete data;

- selective outcome reporting;

- other sources of bias, such as financial conflicts of interest and single author or single centre trials.

Each criterion was assigned a judgement of 'high risk', 'low risk' or 'unclear risk' relating to the risk of bias for that entry. 'Unclear risk' indicates an unclear or unknown risk of bias; or if an entry was not relevant to the study being considered. Results are presented in the 'Risk of bias' graph (Figure 1). A 'Risk of bias summary' figure was generated using Review Manager 5 to present all of the judgements in a cross-tabulation of study by entry (Figure 2; RevMan 2014).

Figure 1. Risk of bias graph: review authors' judgements about each risk of bias item presented as percentages across all included studies.

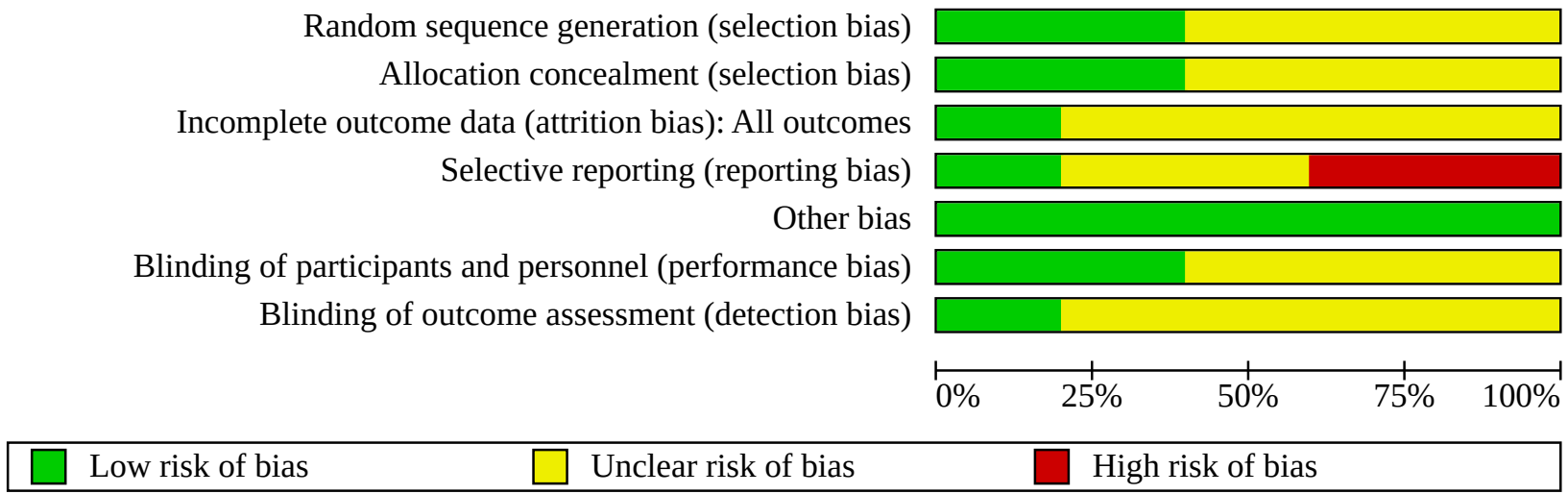


Figure 2. Risk of bias summary: review authors' judgements about each risk of bias item for each included study.

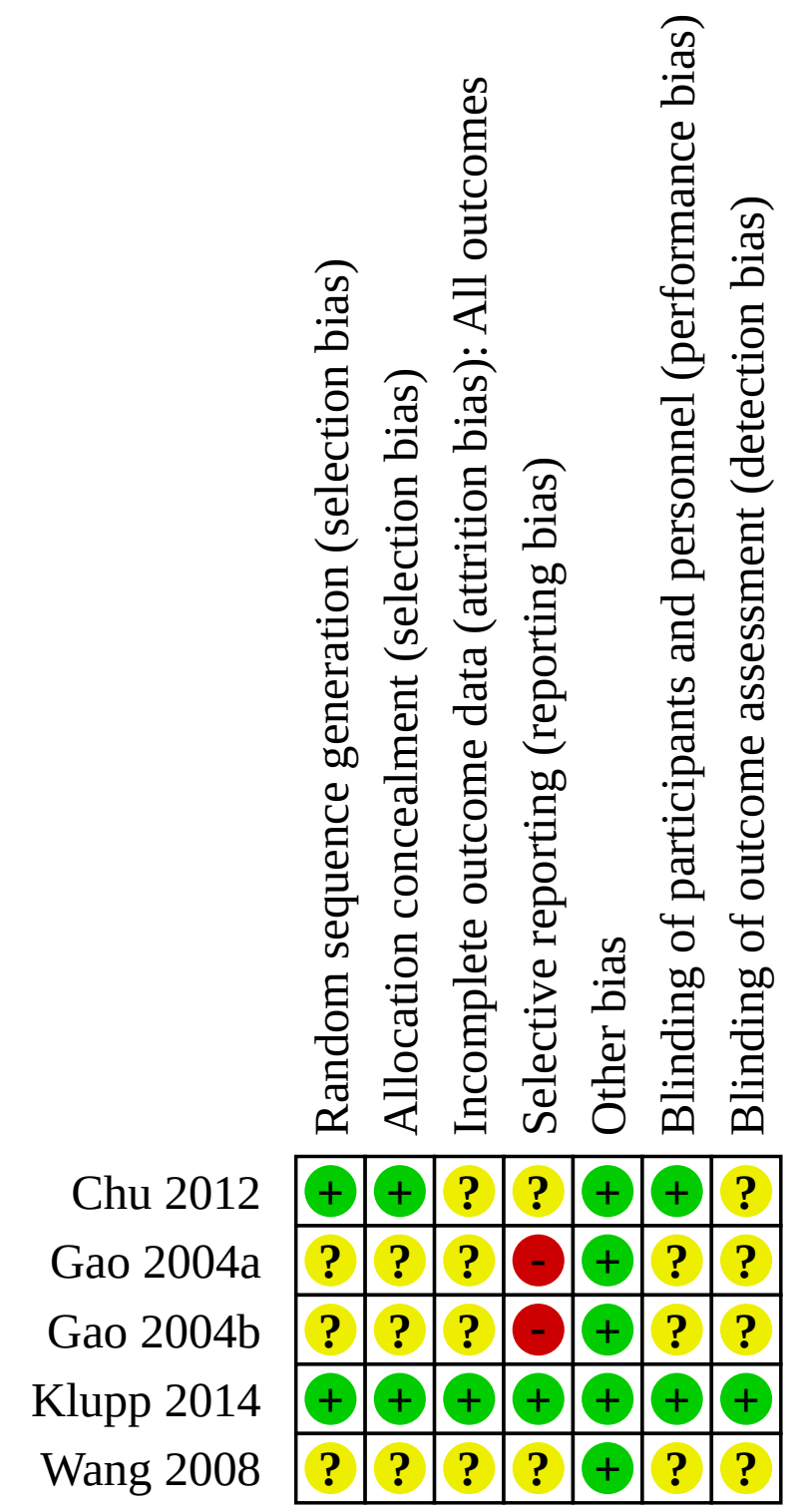

\section{Measures of treatment effect}

We used mean endpoint scores for inter-group comparisons. For pooled continuous data, we calculated weighted mean differences with $95 \%$ confidence intervals $(\mathrm{Cl})$ when measurement scales were the same. If different measurement scales were used in trials, we planned to perform standardised mean difference analyses. We converted outcome measures to metric values where possible, e.g. $\mathrm{mg} / \mathrm{dL}$ was converted to $\mathrm{mmol} / \mathrm{L}$. We used the conservative random-effects model unless the degree of heterogeneity was readily explainable, or when the measure of heterogeneity $1^{2}$ was less than $25 \%$, in which case we used the fixed-effect model
(Higgins 2011). All quantitative analyses adhered to intention-totreat models where possible, whereby participants were analysed according to the original group to which they were assigned.

We calculated risk ratio (RR) with $95 \% \mathrm{Cl}$ for dichotomous data.

\section{Unit of analysis issues}

For cross-over trials we specified that only the first phase of intervention was to be included as there are currently insufficient data to determine the minimum washout period for G lucidum. 


\section{Dealing with missing data}

Where possible, data were extracted from intention-to-treat analyses. If data or study information were missing, we contacted the first or corresponding author for further information. Additional information retrieved from authors was italicised in extraction forms and is clearly indicated in the review text.

\section{Assessment of heterogeneity}

We pooled data in meta-analysis if trials were sufficiently clinically homogenous for participants, interventions and outcomes. We used the $\mathrm{Chi}^{2}$ test for heterogeneity to obtain the 12 statistic, which describes the proportion of inter-trial statistical inconsistency. We interpreted $\mathrm{I}^{2}$ values using the following guide:

- 0 to $40 \%$ might not be important;

- 30 to $60 \%$ may represent moderate heterogeneity;

- 50 to $90 \%$ may represent substantial heterogeneity;

- 75 to $100 \%$ represents considerable heterogeneity.

Where heterogeneity could not readily be explained, we used a random-effects model to incorporate heterogeneous trials in metaanalysis. The statistical heterogeneity of data included in metaanlysis was evaluated visually by inspecting overlap of confidence intervals in forest plots.

\section{Data synthesis}

Statistical analyses were performed with the Cochrane statistical package, Review Manager 5 (RevMan 2014). One reviewer (FH) entered data that were checked by a second reviewer (NK).

\section{Subgroup analysis and investigation of heterogeneity}

We planned to perform subgroup analyses according to:

- dosage where comparable and possible;

- duration of treatment;

- severity of illness; and

- age.
There was an inadequate number of studies to permit subgroup analysis, but this protocol may be used in future updates.

\section{Sensitivity analysis}

Sensitivity analyses were performed by excluding: firstly, unpublished studies; and secondly, studies with high risk of bias. In the event of all studies having a high risk of bias, we planned to perform the sensitivity analysis by excluding studies that did not have adequate allocation concealment or participant blinding. If one or more outliers were thought to contribute to heterogeneity and a reason for the outlying result was apparent, we planned to perform a sensitivity analysis by excluding outliers.

There were an inadequate number of studies for sensitivity analysis according to risk of bias, but this protocol may be used in future updates.

\section{RES U L T S}

\section{Description of studies}

\section{Results of the search}

Electronic searches retrieved a total of 4897 citations (36 from CENTRAL; 71 from PubMed; 1 from Science Direct; 800 from EMBASE; 23 from MD Consult; 13 from Stat!Ref-Medical; 144 from Biomed Central; 407 from Scopus; 439 from CINAHL; 1051 from Current Contents; 462 from Health and Medical Complete; 351 from Science Citations Index; 976 from BIOSIS; 10 from Current Controlled Trials; 9 from Australian New Zealand Clinical Trials Registry; 6 from CentreWatch Clinical Trials Listing Service; 26 from clinicaltrials.gov; 0 from Chinese Biomedical Literature Database; 0 from Chinese Medical Current Contents; 22 from China Network Knowledge Infrastructure; 50 from VIP Database). English language translations of reports published in a Chinese language were obtained, as required, to determine eligibility. Seven studies were identified as being potentially relevant. No additional potentially relevant study was identified by: checking reference lists of included studies; personal communication with authors in the relevant field; medicinal mushroom research centres or relevant pharmaceutical companies; or through handsearching of the International Journal of Medicinal Mushrooms. The study flow chart is provided in Figure 3. 
Figure 3. Study flow diagram.

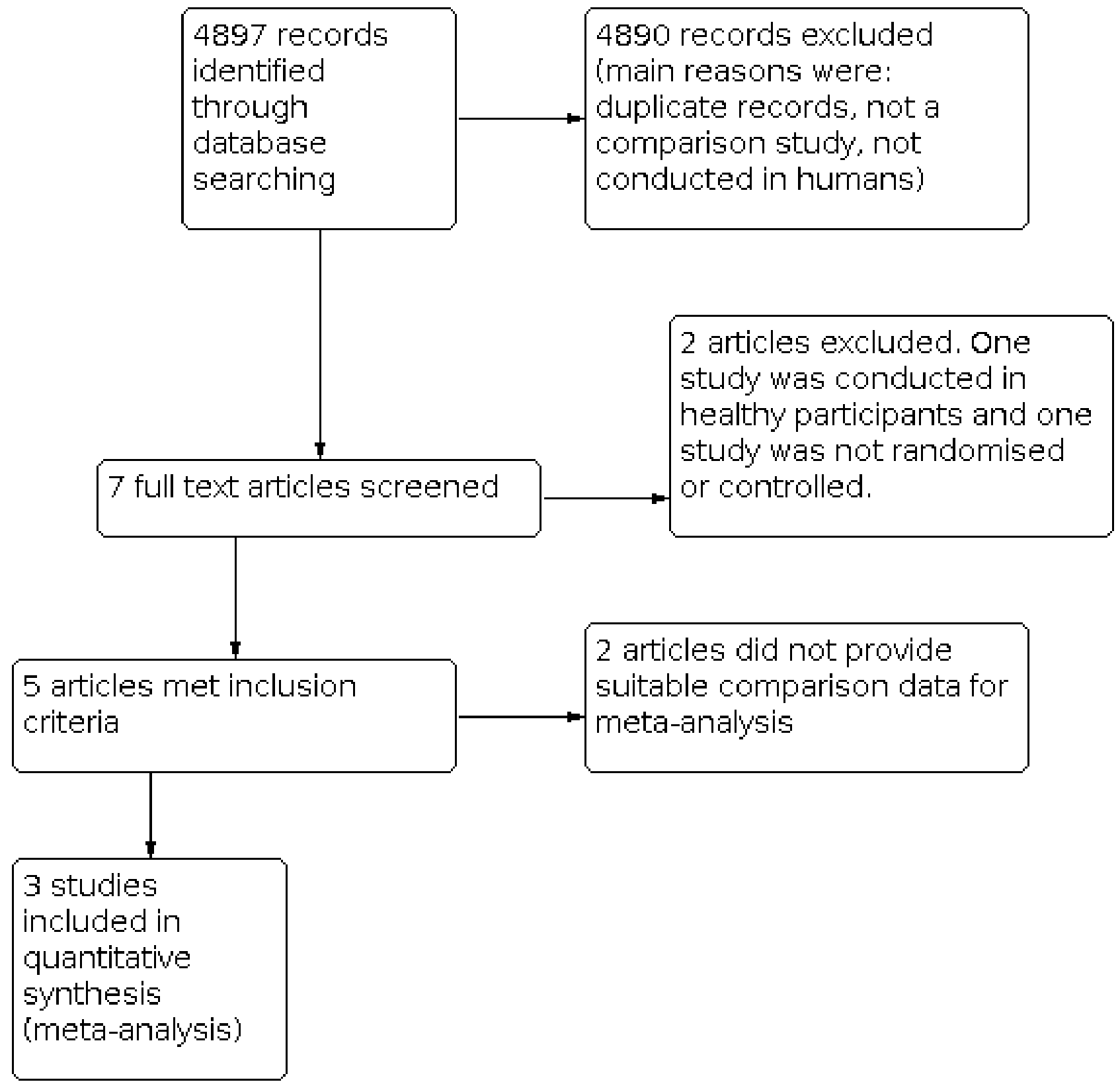

\section{Included studies}

We identified five trials, with a total of 398 participants, that were eligible for inclusion (Chu 2012; Gao 2004a; Gao 2004b; Klupp 2014; Wang 2008). All five trials were identified by electronic searching.

The randomised controlled trial by Klupp was identified as a clinical trial protocol through the Australian New Zealand Clinical Trials Registry (Klupp 2014). Researchers for Klupp 2014 provided unpublished data and additional information for use in this review. The trial evaluated $G$ lucidum ( $3 \mathrm{~g}$ per day) in 84 people with metabolic syndrome and type 2 diabetes mellitus over 16 weeks. Among participants receiving $\mathrm{G}$ lucidum, a subgroup of participants also received Cordyceps sinensis comprising $25 \%$ or less of the total active ingredient. All data provided by Klupp and colleagues is italicised in the table Characteristics of included studies.
The study by Wang was also a randomised controlled trial published in a Chinese language and translated by one review author (HC) (Wang 2008). Wang 2008 evaluated G lucidum (3 g per day) in 50 people with type 2 diabetes mellitus over 12 weeks. It was deemed highly likely that data for fasting plasma glucose contained an error, as the endpoint mean of the placebo group was reported as being 187.9 (49) $\mathrm{mg} / \mathrm{dL}$. Our comparisons and calculations suggest this standard deviation value is not $49 \mathrm{mg} /$ $\mathrm{dL}$, but rather, $4.9 \mathrm{mg} / \mathrm{dL}$. We tried to contact the authors, but all attempts failed. Rather than impute an unconfirmed value, we chose to exclude this data from analysis.

The Chu 2012 study was a cross-over trial from which only pooled data were published. As the protocol specified that only first stage results could be used in meta-analyses, we contacted the authors and they provided first stage data for this review. This unpublished 
data is italicised in the table Characteristics of included studies. The trial duration was 12 weeks and participants took $1.44 \mathrm{~g}$ of G lucidum mushroom capsules per day.

The Gao 2004a study evaluated G lucidum ( $5.4 \mathrm{~g}$ per day) in 71 people with type 2 diabetes mellitus over 12 weeks. In another trial, Gao 2004b, Gao evaluated G lucidum (5.4 g per day) in 170 people with coronary heart disease over 12 weeks. Gao 2004a and Gao 2004b did not report data suitable for determining betweengroup comparison effect sizes. The authors did not respond to our requests for additional information. As a result, both these studies could not be included in meta-analyses.

\section{Excluded studies}

All but seven of the 4897 records we identified were excluded following screening of abstracts. The majority of these citations referred to studies that were not human trials or were not comparison trials. Two of the potentially relevant trials were excluded upon reading the full-text versions (see Characteristics of excluded studies). Jin 1996 was not a randomised or controlled clinical trial and Wachtel-Galor 2004 studied effects in healthy participants. Figure 3 presents the flow of study search results.

\section{Risk of bias in included studies}

Risk of bias of included studies is presented in Figure 1 and summarised in Figure 2. Only one trial was evaluated as having a low risk of bias for all items (Klupp 2014). The Chu 2012 study was designated as unclear for 'incomplete outcome data', 'selective outcome reporting' and 'outcome assessment blinding'; the other four items were changed from unclear to low risk of bias following communication with the study authors. The Wang 2008 study was designated as having an unclear risk of bias for all items, except for 'other bias', which presented a low risk. Gao 2004a and Gao $2004 \mathrm{~b}$ both had unclear risk of bias for most items; the exceptions were for 'other bias', that was deemed to be low risk, and 'selective reporting' that was considered to have a high risk of bias.

\section{Random sequence generation (selection bias)}

Two trials reported random sequence generation using a computer (Chu 2012; Klupp 2014). The process of random sequence generation for other trials was unclear (Gao 2004a; Gao 2004b; Wang 2008).

\section{Allocation concealment (selection bias)}

Two trials reported concealing allocation order by using coded bottles labelled off-site by staff who were not associated with the research (Chu 2012; Klupp 2014). It is not clear whether or not the other trials concealed allocation order.

\section{Incomplete outcome data (attrition bias)}

One trial provided sufficient information to permit judgement regarding risk of bias due to completeness of outcome data (Klupp 2014). In the Klupp 2014 trial, missing outcome data were balanced in numbers across groups (with similar reasons for missing data across groups), reasons for missing outcome data were unlikely to be related to the true outcome, and missing data were imputed using appropriate methods. All the other studies reported insufficient information to permit a judgement of risk of bias to be made.

\section{Selective reporting (reporting bias)}

One trial pre-specified primary outcomes and reported complete results according to its protocol (Klupp 2014). Gao 2004a and Gao 2004b did not specify primary outcomes, selectively reported key expected outcomes and presented incomplete results for outcomes. No data from these studies could be used in metaanalyses. Notably, Gao 2004a did not report data for fasting plasma glucose, which is an expected primary outcome for a clinical trial on diabetes mellitus. Both Gao 2004a and Gao 2004b were judged to have a high risk of reporting bias due to selective reporting. Wang 2008 did not specify primary outcome measures and it is unclear whether reported outcomes were selected from a larger number of outcomes, so Wang 2008 was judged as having an unclear risk of bias. Chu 2012 was also designated as having an unclear risk of bias because it did not specify primary outcome measures and no protocol was available.

\section{Blinding of participants and personnel (performance bias)}

Two trials reported sufficient information to permit a judgement of low risk of bias (Chu 2012; Klupp 2014). Three trials did not report sufficient information to permit a judgement of risk of bias (Gao 2004a ;Gao 2004b; Wang 2008), as although they reported using a placebo intervention, there were no details about blinding of personnel.

\section{Blinding of outcome assessment (detection bias)}

One trial reported sufficient information to permit a judgement of low risk of bias (Klupp 2014). The remaining four trials did not report sufficient information to permit a judgement of risk of bias (Chu 2012; Gao 2004a; Gao 2004b; Wang 2008). All five trials were at low risk of "other biases".

\section{Effects of interventions}

Details of all interventions are provided in the table Characteristics of included studies. Three of the five trials, Klupp 2014, Chu 2012 and Wang 2008, presented summary statistics appropriate for use in analyses. Gao 2004a and Gao 2004b did not report data suitable for use in between-group comparisons and the authors did not respond to our requests for additional information.

Comparisons are ordered according to the Types of outcome measures in the methods section. Analyses containing data from only one study are summarised in Table 1 and Table 2 . Analyses containing data from more than one study are summarised in forest plots.

\section{Fasting plasma glucose}

Klupp 2014 compared the effect on fasting plasma glucose of $G$ lucidum with placebo at 8,16 and 24 weeks. The intervention period was 16 weeks, followed by an observational wash-out period of eight weeks. Wang 2008 also compared G lucidum with placebo for this outcome at 12 weeks, however we are certain that these data contain an error and have excluded them from our analysis. Results are provided as weighted mean differences (WMD). Differences in fasting plasma glucose between groups in Klupp 2014 were not statistically significant after eight weeks (WMD $0.80 \mathrm{mmol} / \mathrm{L} ; 95 \%$ $\mathrm{Cl}-0.35$ to 1.95; Table 1), 12 to 16 weeks (WMD $0.30 \mathrm{mmol} / \mathrm{L} ; 95 \% \mathrm{Cl}$ -0.95 to 1.55 ; Table 1 ), or 24 weeks (WMD $1.00 \mathrm{mmol} / \mathrm{L} ; 95 \% \mathrm{Cl}-0.18$ to 2.18; Table 1). 


\section{HbA1c}

For HbA1c we pooled data from Wang 2008 and Klupp 2014. There was no statistically significant difference in $\mathrm{HbA1c}$ between group at 8-weeks (WMD $0.30 \%$; $95 \% \mathrm{Cl}-0.33$ to 0.93 ; Table 1 ). We pooled the 12 week data from Wang 2008 with 16-week data from Klupp 2014 and also found no statistically significant difference (WMD $-0.07 \% 95 \% \mathrm{Cl}-0.57$ to 0.42 ; Analysis 1.1 ). However there was statistical significance in favour of the placebo group at 24 weeks (WMD 0.70\%; 95\% Cl 0.06 to 1.34; Table 1) after the washout period. As per protocol, sensitivity analysis was performed for the 12 to 16 week meta-analysis by excluding unpublished data from the Klupp 2014 trial; the difference in fasting plasma glucose between groups was not statistically significant (WMD $-0.60 \mathrm{mmol} / \mathrm{L} ; 95 \% \mathrm{Cl}-1.34$ to 0.14).

\section{2-hour post prandial blood glucose}

Wang 2008 compared G lucidum with placebo at 12 weeks, when there was a statistically significant difference between groups for 2-hour post prandial blood glucose in favour of placebo (WMD 0.7 $\mathrm{mmol} / \mathrm{L} ; 95 \% \mathrm{Cl} 0.29$ to 1.11 ; Table 1 ).

\section{Plasma glucose under the curve at 4th hour of meal tolerance test}

Wang 2008 compared G lucidum with placebo at 12 weeks, when there was a statistically significant difference between groups in plasma glucose under the curve at 4 th hour of meal tolerance test in favour of $\mathrm{G}$ lucidum (WMD $-49.40 \mathrm{mg} / \mathrm{dL} / \mathrm{h} ; 95 \% \mathrm{Cl}-77.21$ to -21.59 ; Table 1).There is a paucity of information regarding normal and atypical responses to four-hour glucose tolerance testing, making determination of clinical significance difficult.

\section{Arterial pressure}

Klupp 2014 compared G lucidum with placebo at 8, 16 and 24 weeks. Differences in arterial pressure between groups were not statistically significant after eight weeks (WMD $1.90 \mathrm{mmHg} ; 95 \% \mathrm{Cl}$ -33.62 to 37.42 ; Table 1), 16 weeks (WMD $0.30 \mathrm{mmHg} ; 95 \% \mathrm{Cl}-4.59$ to 5.19; Table 1), or 24 weeks (WMD $-3.20 \mathrm{mmHg} ; 95 \% \mathrm{Cl}-8.66$ to 2.26; Table 1).

\section{Triglycerides}

Klupp 2014 compared $G$ lucidum with placebo at 8, 16 and 24 weeks. Differences in triglycerides between groups were not statistically significant after eight weeks (WMD $-0.10 \mathrm{mmol} / \mathrm{L} ; 95 \% \mathrm{Cl}-0.47$ to 0.27; Table 1), 16 weeks (WMD $0.3 \mathrm{mmol} / \mathrm{L} ; 95 \% \mathrm{Cl}-0.43$ to 1.03 ; Table 1), or 24 weeks (WMD $-0.10 \mathrm{mmol} / \mathrm{L} ; 95 \% \mathrm{Cl}-0.68$ to 0.48 ; Table $1)$.

\section{Total cholesterol}

We pooled the 12-week data from Chu 2012 with the 16 week data from Klupp 2014 for meta-analysis. Differences in total cholesterol between groups were not statistically significant at eight weeks (WMD $-0.20 \mathrm{mmol} / \mathrm{L} ; 95 \% \mathrm{Cl}-0.71$ to 0.31 ; Table 1 ), 12 to 16 weeks (WMD $-0.07 \mathrm{mmol} / \mathrm{L} ; 95 \% \mathrm{Cl}-0.57$ to 0.43 ; Analysis 1.2 ), or 24 weeks (WMD $-0.30 \mathrm{mmol} / \mathrm{L} ; 95 \% \mathrm{Cl}-0.84$ to 0.24 ; Table 1 ). Sensitivity analysis could not be performed for the 12 to 16 week meta-analysis because data from both studies was unpublished.

\section{High density lipoprotein}

Klupp 2014 compared G lucidum with placebo at 8, 16 and 24 weeks. Differences in high density lipoprotein between groups were not statistically significant after eight weeks (WMD $0.10 \mathrm{mmol} / \mathrm{L} ; 95 \% \mathrm{Cl}$ -0.05 to 0.25 ; Table 1 ), 16 weeks (WMD $0.00 \mathrm{mmol} / \mathrm{L} ; 95 \% \mathrm{Cl}-0.13$ to 0.13 ; Table 1), or 24 weeks (WMD $0.00 \mathrm{mmol} / \mathrm{L} ; 95 \% \mathrm{Cl}-0.15$ to 0.15 ; Table 1).

\section{Low density lipoprotein}

We pooled the 12-week data from Chu 2012 with the 16 week data from Klupp 2014 for meta-analysis. Differences in low-density lipoprotein between groups were not statistically significant at eight weeks (WMD $0.10 \mathrm{mmol} / \mathrm{L} ; 95 \% \mathrm{Cl}-0.39$ to 0.59 ; Table 1 ); 12 to 16 weeks (WMD 0.02; 95\% Cl: -0.41 to 0.45 ; Analysis 1.3), or 24 weeks (WMD $-0.30 \mathrm{mmol} / \mathrm{L} ; 95 \% \mathrm{Cl}-0.74$ to 0.14 ; Table 1 ). Sensitivity analysis could not be performed for the 12 to 16 week meta-analysis because data from both studies was unpublished.

\section{Waist circumference}

Klupp 2014 compared G lucidum with placebo at 8, 16 and 24 weeks. Differences in waist circumference between groups were not statistically significant after eight weeks (WMD $-0.05 \mathrm{~cm} ; 95 \% \mathrm{Cl}$ -7.38 to 6.38 ; Table 1 ), 16 weeks (WMD $-2.8 \mathrm{~cm} ; 95 \% \mathrm{Cl}-9.28$ to 3.68 ; Table 1), or 24 weeks (WMD $-0.2 \mathrm{~cm} ; 95 \% \mathrm{Cl}-6.53$ to 6.13; Table 1 ).

\section{Body mass index}

We pooled the 12-week data from Chu 2012 with the 16 week data from Klupp 2014 for meta-analysis. Differences in body mass index between groups were not statistically significant at eight weeks (WMD $0.10 ; 95 \% \mathrm{Cl}-3.14$ to 3.34 ; Table 1 ) or 12 to 16 weeks (WMD -0.32 : $95 \%$ Cl: -2.67 to 2.03; Analysis 1.4), or 24 weeks (WMD 1.30; $95 \% \mathrm{Cl}-1.81$ to 4.41 ; Table 1 ). Sensitivity analysis could not be performed for the 12 to 16 week meta-analysis because data from both studies were unpublished.

\section{C-reactive protein}

Klupp 2014 compared G lucidum with placebo at 8, 16 and 24 weeks. Differences in C-reactive protein between groups were not statistically significant after eight weeks (WMD $-1.50 \mathrm{mg} / \mathrm{L} ; 95 \% \mathrm{Cl}$ -3.09 to 0.09 ; Table 1 ), 16 weeks (WMD $-0.20 \mathrm{mg} / \mathrm{L} ; 95 \% \mathrm{Cl}-2.64$ to 2.24; Table 1), or 24 weeks (WMD $2.10 \mathrm{mg} / \mathrm{L} ; 95 \% \mathrm{Cl}-0.96$ to 5.16; Table 1)

\section{Apolipoprotein A}

Klupp 2014 compared G lucidum with placebo at 8, 16 and 24 weeks. There was no statistical significant difference at 16 weeks (WMD $0.00 \mathrm{~g} / \mathrm{L} ; 95 \% \mathrm{Cl}-0.13$ to 0.13 ; Table 1). After eight weeks and 24 weeks differences in apolipoprotein $A$ between groups were statistically significant and favoured placebo (8 weeks WMD -0.60 $\mathrm{g} / \mathrm{L} ; 95 \% \mathrm{Cl}-0.73$ to -0.47 ; Table $1 ; 24$ weeks WMD $-0.60 \mathrm{~g} / \mathrm{L} ; 95 \% \mathrm{Cl}$ -0.73 to -0.47 ; Table 1$)$.

\section{Apolipoprotein B}

Klupp 2014 compared $G$ lucidum with placebo at 8,16 and 24 weeks. After eight weeks the difference in apolipoprotein B between groups was statistically significant in favour of the placebo group (WMD $0.20 \mathrm{~g} / \mathrm{L} ; 95 \% \mathrm{Cl} 0.11$ to 0.29 ; Table 1 ), but not after 16 weeks (WMD $0.00 \mathrm{~g} / \mathrm{L} ; 95 \% \mathrm{Cl}-0.13$ to 0.13 ; Table 1 ), or 24 weeks (WMD 0.00 $\mathrm{g} / \mathrm{L} ; 95 \% \mathrm{Cl}-0.12$ to 0.12 ; Table 1 ) 


\section{Health-related quality of life (physical)}

Klupp 2014 compared G lucidum with placebo at 8, 16 and 24 weeks. Differences between groups in health-related quality of life (physical) were not statistically significant after eight weeks (WMD $-2.55 ; 95 \% \mathrm{Cl}-5.78$ to 0.68 ; Table 1), 16 weeks (WMD $-0.10 ; 95 \% \mathrm{Cl}$ -3.96 to 3.76; Table 1), or 24 weeks (WMD $0.20 ; 95 \% \mathrm{Cl}-3.77$ to 4.17 ; Table 1)

\section{Health related quality of life (mental)}

Klupp 2014 compared G lucidum with placebo at 8, 16 and 24 weeks. Differences between groups in health-related quality of life (mental) were not statistically significant after eight weeks (WMD $-0.07 ; 95 \% \mathrm{Cl}-4.78$ to 4.64 ; Table 1), 16 weeks (WMD 0.00; $95 \% \mathrm{Cl}$ -5.42 to 5.42 ; Table 1 ), or 24 weeks (WMD $-0.40 ; 95 \% \mathrm{Cl}-4.90$ to 4.10 ; Table 1).

\section{Adverse events}

Klupp 2014 compared G lucidum with placebo control from 0 to 16 weeks (intervention period), and from 16 to 24 weeks (observational wash-out period). Differences between groups for adverse events were not statistically significant over the 16week intervention period (RR $1.67 ; 95 \% \mathrm{Cl} 0.86$ to 3.24; Table 2). Anticipated adverse events for this intervention included mild gastrointestinal effects such as nausea, diarrhoea or constipation. For these mild gastrointestinal events there were also no significant differences (RR 1.25; 95\% Cl 0.62 to 2.53; Table 2). There was also no difference between groups during the follow-up period of 16 to 24 weeks for adverse events (RR $1.11 ; 95 \% \mathrm{Cl} 0.42$ to 2.95 ; Table 2) including mild gastrointestinal effects (RR $0.56 ; 95 \% \mathrm{Cl} 0.01$ to 8.57 ; Table 2). No participant in either group demonstrated any adverse effect to the liver. One participant demonstrated an adverse effect to the kidney, which occurred in the 16 to 24 week non-intervention period.

\section{DISCUSSION}

\section{Summary of main results}

This review includes five studies; four published and one unpublished; we obtained additional unpublished data suitable for use in this review for one of the published studies. Two of the published studies did not provide control group data and therefore could not be used for statistical analysis (Gao 2004a; Gao 2004b). Published data from the Wang 2008 study, and unpublished data provided by researchers for the Klupp 2014 and Chu 2012 studies were suitable for analysis. The daily dose of $G$ lucidum used in the Chu 2012 study was 1.44 g, while both the Wang 2008 and Klupp 2014 studies used $3 \mathrm{~g}$. Participants of these three studies had type 2 diabetes mellitus. Wang 2008 evaluated 50 participants over 12 weeks, Chu 2012 evaluated 23 participants over 12 weeks and Klupp 2014 evaluated 84 participants over 16 weeks. There were three primary, and one secondary, outcome comparisons suitable for meta-analysis.

At the end of the intervention period in people taking $G$ lucidum, there was no statistically or clinically significant improvement in $\mathrm{HbA1c}$ (WMD $-0.07 ; 95 \% \mathrm{Cl}-0.57$ to 0.42 ; Analysis 1.1 ), total cholesterol (WMD - $0.07 ; 95 \% \mathrm{Cl}-0.57$ to 0.43 ; Analysis 1.2 ), lowdensity lipoprotein cholesterol (WMD $0.0295 \% \mathrm{Cl}-0.41$ to 0.45 ; Analysis 1.3) or body-mass index (WMD $-0.3295 \% \mathrm{Cl}-2.67$ to 2.03; Analysis 1.4). All other analyses were from single studies. Single study analysis from Klupp 2014 found an improvement of $0.7 \%$ in $\mathrm{HbA} 1 \mathrm{c}$ for those in the placebo group $(95 \% \mathrm{Cl} 0.06$ to 1.34$)$ after an eight-week post-intervention washout period. No difference was found between groups during, or after, the intervention period for fasting plasma glucose. Single study results from Wang 2008 for post-prandial glucose were mixed. Analysis of '2-hour post-prandial blood glucose' found a statistically significant reduction of 0.7 $\mathrm{mmol} / \mathrm{L}(95 \% \mathrm{Cl} 0.29$ to 1.11$)$ for those taking placebo, however, the same study found statistical significance favouring $G$ lucidum for another post-prandial measure 'plasma glucose under the curve at 4 th hour'. The difference between groups was $-49.4 \mathrm{mg} / \mathrm{dL} / \mathrm{h}$ (95\% Cl -77.21 to -21.59$)$, but there was a paucity of information regarding normal and atypical curve values for 4-hour glucose tolerance testing, making determination of clinical significance difficult. For the other primary outcome measures, there was single study evidence of no effect for blood pressure and triglyceride levels.

Secondary outcomes showed an improvement in apolipoprotein $A$ of $0.6 \mathrm{~g} / \mathrm{L}(95 \% \mathrm{Cl} 0.47$ to 0.73$)$ at eight weeks and $0.6 \mathrm{~g} / \mathrm{L}(95 \%$ $\mathrm{Cl} 0.47$ to 0.73 ) at 24 weeks for the placebo group in the Klupp 2014 study. This study also showed a statistically significant effect in favour of the placebo group for apolipoprotein B at eight weeks $0.20 \mathrm{~g} / \mathrm{L}(95 \% \mathrm{Cl} 0.11$ to 0.29$)$ but not at 16 or 24 weeks. None of these results are suggest harm from $G$ lucidum. We found no statistically significant differences between groups for any other secondary outcome measure. These included waist circumference, body mass index, C-reactive protein and health-related quality of life.

Only the Klupp 2014 study provided data regarding safety. Participants who took G lucidum were 1.67 times more likely (95\% $\mathrm{Cl} 0.86$ to 3.24) to have an adverse event than those taking placebo, but this was not a statistically significantly greater risk (Klupp 2014). The increased risk of anticipated mild gastrointestinal events, such as nausea, diarrhoea or constipation, was RR $1.25(95 \% \mathrm{Cl} 0.62$ to 2.53) for those taking $G$ lucidum. There were no adverse events affecting the liver in either group. One participant experienced an adverse event of the kidney during the non-intervention period between weeks 16 to 24 . These safety results should be interpreted with caution due to the low sample size available to detect adverse events.

\section{Overall completeness and applicability of evidence}

This review searched a comprehensive range of databases, including Chinese language databases. No language restrictions were placed on the search and screening stages, and subsequently, a Chinese language publication was included in this review. Both the English and Chinese searches were updated before review finalisation.

Only three of the five included studies, Wang 2008; Chu 2012 and Klupp 2014, reported data suitable for analysis. The Gao 2004a and Gao 2004b study publications did not report any control group data. As these authors did not, or could not, respond to requests for additional information, data from these two published clinical trials could not be included in this review. Although single study data were available for all primary outcomes, meta-analysis (from two studies) could only be performed for $\mathrm{HbAlc}$, total cholesterol, low-density lipoprotein and body mass index. Although fasting plasma glucose was evaluated in two studies, there was a high probability of error in the Wang 2008 data and so it was excluded 
from analysis. We were unable to make contact with these authors. Secondary outcome measures that were specified in the protocol but not evaluated by studies in this review included levels of insulin, fibrinogen and homocysteine. Furthermore, where analyses were conducted from single studies, there is a greater chance of outcomes being under-powered. This is particularly important for more variable outcomes, such as blood pressure.There were also multiple outcome measures from the Chu 2012 study that had baseline mean data that were within normal ranges, and according to the protocol, could not be included in analyses. Only the Klupp 2014 study evaluated the safety of G lucidum.

The three studies that contributed data for meta-analyses evaluated $\mathrm{G}$ lucidum at a dosage of $1.4 \mathrm{~g}$ to $3 \mathrm{~g}$ per day for 12 to 16 weeks. The 24 week analyses in Klupp 2014 also evaluated effects on outcomes after eight weeks without intervention. The effect on outcomes might differ if taken in higher doses or for longer treatment periods. However, the highest weighted study, Klupp 2014, reported that participants were required to take eight capsules per day in order to ingest $3 \mathrm{~g}$ of $\mathrm{G}$ lucidum extract, which suggests compliance might be a barrier for studies evaluating higher dosages of a similar intervention.

\section{Judgement of external validity}

This review includes a limited number of studies and only four outcome measures could be analysed with pooled data. Therefore, most results in this review represent settings and participants of single clinical trials. Reporting limitations for Wang 2008 have implications for external validity, as no information was provided regarding recruitment, setting or country. The Klupp 2014 trial recruited from the general community across Sydney, Australia and the Chu 2012 trial was conducted in Hong Kong, China. All three studies used for analyses evaluated effects of $G$ lucidum in people with type 2 diabetes mellitus. The participants of the Klupp 2014 study also had metabolic syndrome. The inclusion criteria for the Chu 2012 trial included hypertension and hyperlipidaemia, but not all outcome measure group means were found to be pathologically elevated at baseline. These studies did not evaluate $G$ lucidum for prevention of type 2 diabetes mellitus and other cardiovascular risk factors, and did not include participants with impaired glucose tolerance (pre-diabetes).The results of this review also cannot be generalised to those with more severe health presentations that were specified as exclusion criteria of the studies. These include people with renal or hepatobiliary impairment, hypoglycaemic events or requiring insulin or periods of hospitalisation. Klupp 2014 also reported that pregnant women were excluded. Although Wang 2008 and Chu 2012 did not specify that pregnant women were excluded, the results of this review should not be assumed applicable to gestational diabetes.

G lucidum is most commonly used in traditional Chinese medicine, but is increasingly being used in western society. This review aimed to evaluate efficacy and safety of $G$ lucidum for treatment of cardiovascular risk factors. In traditional Chinese medicine, the diagnostic approach to cardiovascular risk differs from that presented in this review, and the intervention is unlikely to be prescribed in isolation. As such, the results of this review are more relevant for application in western medicine and less relevant for application within a traditional Chinese medicine paradigm.

\section{Risk of bias}

The lack of quality reporting for four of the five studies impacts on the results of this review (Chu 2012; Gao 2004a; Gao 2004b; Wang 2008). No data from Gao 2004a and Gao 2004b could be included in analyses. The only published study from which data was extracted for use in this review had unclear risk of bias for nearly all items (Wang 2008). Although the cross-over Chu 2012 trial was published in 2012, this publication did not include the first stage data or information to permit us to determine risk of bias. Further information was provided by the authors, but this has not been previously subjected to peer review. Although Klupp 2014 was judged to have a low risk of bias for all items, the information from this trial is, as yet, unpublished and so has not been subjected to peer review yet. Although there were no significant results regarding effectiveness of $G$ lucidum and all forest plot confidence intervals significantly overlapped, there was a trend that results from Wang 2008 and Chu 2012 slightly favoured G lucidum compared to those from Klupp 2014. It is possible that the assessment of a lower risk of bias for the Klupp 2014 study partially explains this trend. Overall, due to limitations and concerns about quality, a robust conclusion cannot be drawn for consistency, size and direction of outcome effects in this review.

\section{Potential biases in the review process}

A potential bias for this review is that the data that we included from the Klupp 2014 and Chu 2012 trials is unpublished. Furthermore, the trial authors of the Klupp 2014 study are also authors of this review (NK, FH, DC, $A B$ and $H K$ ). However, the clinical trial was registered with the Australia New Zealand Clinical Trial Registry and all data provided by NK is consistent with the published online protocol. The characteristics and potential for bias of Klupp 2014 were independently evaluated by one other author $(\mathrm{HC})$, who is not involved in the clinical trial.

We experienced challenges accessing Chinese literature about $G$ lucidum. Much of the knowledge base is grey literature, which our search strategy might not have captured. Also, until recently, research in traditional Chinese medicine did not utilise placebo or control groups as a standard feature of clinical trials. Although excluding this research does not introduce bias, it is important to note that there is an evidence base in China unsuitable for inclusion in a systematic review such as this. G lucidum might also have been combined with multiple herbal interventions, as is frequently the practice in eastern medicine. A further potential for bias was that only one author was able to screen Chinese titles and abstracts for inclusion.

\section{Agreements and disagreements with other studies or reviews}

At present this is the only systematic review evaluating $G$ lucidum for cardiovascular risk factors. We have aimed to include all randomised and controlled clinical trials on this topic.

Commentary on this topic frequently reports positive findings from the literature for effectiveness of $G$ lucidum. These reports are frequently based on animal, in vitro or human case studies. Any larger human research studies are often pre-test/post test designs without comparative controls. Such studies are unsuitable for determining efficacy and safety in humans. 
There is disagreement between the studies included in this review. One study reported that taking $G$ lucidum reduced blood glucose and improved diabetes (Gao 2004a). Despite conducting a doubleblind randomised study, the publication only described pre-test/ post test results for the intervention group, and therefore its data could not be included in statistical analysis. Its likely that these within-group changes would find greater effect sizes, favouring intervention, than the between-group comparisons as used in this review. Gao 2004b also reported that G lucidum improved blood pressure and cholesterol, but selective reporting and unclear between-group analyses similarly exposed a high risk of biased positive results. These were the key reasons that Gao 2004a and Gao 2004b could not be included in meta-analysis.

The Wang 2008 study described that there was a greater reduction for 2-hour post-prandial glucose in the G lucidum group, which differed from our result of statistical significance in favour of placebo. These findings might differ depending on whether endpoint or change scores were used for analyses. As per Cochrane recommendations, our protocol specified that endpoint scores would be used for all analyses, whereas the Wang 2008 trial report appears to have described change scores. The Chu 2012 study also reported that $G$ lucidum provided mild antidiabetic and antidyslipidaemic effects. We could not analyse all outcome measures from this study, however our results for total cholesterol and low-density lipoprotein do not support these modest claims.

\section{AUTHORS' CONCLUSIONS}

\section{Implications for practice}

We found a lack of evidence on the efficacy and safety of Ganoderma lucidum. Evidence from existing randomised and controlled trials does not support the use of $G$ lucidum for treatment of cardiovascular risk factors. Our evidence is limited to three studies in which all participants had type 2 diabetes mellitus. There was evidence of no effect for the primary outcomes of this review; $\mathrm{HbA1c}$, fasting plasma glucose, blood pressure, triglycerides and cholesterol profile. There were mixed findings regarding post- prandial glucose from a single study. These results are for effects of $\mathrm{G}$ lucidum at a dosage of $1.4 \mathrm{~g}$ to $3 \mathrm{~g}$ daily for 12 to 16 weeks. There was inadequate evidence to determine whether $G$ lucidum is safe for cardiovascular risk factors. Larger sample sizes are required to detect risk of adverse events. From the trials in this review, we found some increase in risk of anticipated mild gastrointestinal adverse events for those taking G lucidum, but these were not statistically significant. There was no evidence of hepatic effects. One participant had an adverse event affecting the kidneys in the non-intervention period. The evidence base for treating cardiovascular risk factors with $G$ lucidum is weakened by methodological and reporting quality limitations. This review evaluated $G$ lucidum in a western medicine context, and therefore results might be less generalisable to traditional Chinese medicine.

\section{Implications for research}

Research into efficacy and safety of $G$ lucidum for treatment of cardiovascular risk factors is in its infancy. Much of the research conducted thus far is difficult to evaluate because of poor quality reporting. Future studies should be designed to ensure low risk of bias and to meet current reporting standards for clinical trials.

Recommendations to improve the evidence base of $G$ lucidum for cardiovascular risk factors include increased sample size for some outcome measures not adequately powered by existing studies (for example, blood pressure); furthermore, efficacy should be evaluated in people with impaired glucose tolerance for prevention of diabetes, in people with more severe presentations of diabetes and cardiovascular disease, and within a traditional Chinese medicine context. An increased sample size is also required to detect whether there is meaningful risk of rare or serious adverse events.

\section{ACKNOWLEDGEMENS}

The reviewers wish to thank the editorial team of the Cochrane Heart Group and the Australasian Cochrane Centre for their assistance in the preparation of this review. 


\section{R E F E R E N C E S}

\section{References to studies included in this review}

Chu 2012 \{unpublished data only\}

Chu TT, Benzie IF, Lam CW, Fok BS, Lee KK, Tomlinson B. Study of potential cardioprotective effects of Ganoderma lucidum (Lingzhi): results of a controlled human intervention trial. British Journal of Nutrition 2012;107:1017-27.

Gao 2004a \{published data only\}

Gao YH, Lan J, Dai XH, Ye JX, Zhou SF. A phase I/II study of Ling Zhi mushroom Ganoderma lucidum (W.Curt.:Fr.) Lloyd (Aphyllophoromycetideae) extract in patients with type II diabetes mellitus. International Journal of Medicinal Mushrooms 2004;6:33-9.

\section{Gao 2004b \{published data only\}}

Gao YH, Chen GL, Dai XH, Ye JX, Zhou SF. A phase I/II study of Ling Zhi mushroom Ganoderma lucidum (W.Curt.:Fr.) Lloyd (Aphyllophoromycetideae) extract in patients with coronary heart disease. International Journal of Medicinal Mushrooms 2004;6(4):327-34.

\section{Klupp 2014 \{published data only\}}

Klupp NL, Bensoussan A, Kiat H, Hawke F, Chang D. Ganoderma lucidum for hyperglycaemia in persons with metabolic syndrome. Unpublished raw data 2014.

\section{Wang 2008 \{published data only\}}

Wang CW, Tschen J SM, Sheu W HH. Ganoderma lucidum on metabolic control in type 2 diabetes subjects - a double blinded placebo control study. Journal of Internal Medicine of Taiwan 2008;19:54-60.

\section{References to studies excluded from this review}

Jin 1996 \{published data only\}

Jin HM, Zhang GP, Cao X, Zhang M, Long JJ, Luo BQ, et al. Treatment of hypertension by linzhi combined with hypotensor and its effects on arterial, arteriolar and capillary pressure and microcirculation.. In: Microcirculatory approach to Asian traditional medicine. Amsterdam: Elsevier, 1996:131-8.

\section{Wachtel-Galor 2004 \{published data only\}}

Wachtel-Galor S, Tomlinson B, Benzie FF. Ganoderma lucidum ('Lingshi'), a Chinese medicinal mushroom: biomarker responses in a controlled human supplementation study. British Journal of Nutrition 2004;91:263-9.

\section{Additional references}

\section{Capewell 2011}

Capewell S, Ford E, Croft J, Critchley J, Greenland K, Labarthe D. Cardiovascular risk factor trends and potential for reducing coronary heart disease mortality in the United States of America. Bulletin of the World Health Organisation 2010;88:120-30.

\section{Chang 1999}

Chang S, Buswell J. Ganoderma lucidum (Curt.:Fr.) P. Karst. (Aphyllophoromycetideae): a mushrooming medicinal mushroom. International Journal of Medicinal Mushrooms 1999;1:139-46.

\section{Chang 2000}

Chang S-T, Miles P. Mushrooms: Cultivation, nutritional value, medicinal effect and environmental impact. 2nd edition. Boca Raton, USA: CRC Press, 2000. [0-8493-1043-1]

\section{Chen 2004}

Chen J, Chen T. In: Chinese medical herbology and pharmacology. California: Art of Medicine Press, 2004:883-5.

\section{Fatmawati 2011}

Fatmawati S, Shimizu K, Kondo R. Ganoderol B: a potent a-glucosidase inhibitor isolated from the fruiting body of Ganoderma lucidum. Phytomedicine 2011;18:1053-5. [DOI: doi: 10.1016/j.phymed.2011.03.011]

\section{Higgins 2011}

Higgins JP, Green S (editors). Cochrane Handbook for Systematic Reviews of Interventions Version 5.1.0 [updated March 2011]. The Cochrane Collaboration 2011. Available from www.cochrane-handbook.org.

\section{Hikino 1985}

Hikino $\mathrm{H}$, Konno $\mathrm{C}$, Mirin Y, Hayashi T. Isolation and hypoglycemic activity of ganoderans A and B, glycans of Ganoderma lucidum fruit body. Planta Medica August;4:339-40.

\section{Hossain 2007}

Hossain P, Kawar B, El Nahas M. Obesity and diabetes in the developing world - a growing challenge. New England Journal of Medicine 2007;356(3):213-5.

\section{Huie 2004}

Huie C, Di X. Chromatographic and electrophoretic methods for Lingzhi pharmacologically active components. Journal of Chromatography. B, Analytical Techniques in the Biomedical and Life Sciences 2004;812(1-2):241-57.

\section{Kanmatsuse 1985}

Kanmatsuse K, Kajiwara N, Hayashi K, Shimogaichi S, Fukinbara I, Ishikawa H, et al. Studies on Ganoderma lucidum. I. Efficacy against hypertension and side effects. Journal of the Pharmaceutical Society of Japan 1985;105(10):942-7.

\section{Komoda 1989}

Komoda Y, Shimizu M, Sonoda Y, Sato Y. Ganoderic acid and its derivatives as cholesterol synthesis inhibitors. Chemical and Pharmaceutical Bulletin 1989;37(2):531-3.

\section{Lakshmi 2003}

Lakshmi B, Ajith T, Sheena N, Gunapalan N, Janardhanan K. Anti-peroxidative, anti-inflammatory, and antimutagenic activities of ethanol extract of the mycelium of Ganoderma 
lucidum occurring in South India. Teratogenesis, carcinogenesis, and mutagenesis 2003;23(Suppl 1):85-97.

\section{Lee 1990}

Lee S, Rhee H. Cardiovascular effects of mycelium extract of Ganoderma lucidum: Inhibition of sympathetic outflow as a mechanism of its hypotensive action. Chemical and Pharmaceutical Bulletin 1990;38(5):1359-64.

\section{McKenna 2002}

McKenna D, Jones K, Hughes K. Reishi. In: Botanical medicines: The desk reference for major herbal supplements. 2nd edition. Binghamton, New York: The Haworth Herbal Press, 2002:825-55.

\section{Morigawa 1986}

Morigawa A, Kitabatake K, Fujimoto Y, Ikekawa N. Angiotensin converting enzyme-inhibitory triterpenes from Ganoderma lucidum. Chemical and Pharmaceutical Bulletin 1986;34(7):3025-8.

\section{Pearson 2003}

Pearson T, Mensah G, Alexander R, Anderson J, Cannon R, Criqui $\mathrm{M}$, et al. Markers of inflammation and cardiovascular disease: application to clinical and public health practice: a statement for healthcare professionals for the Centers for Disease Control and Prevention and the American Heart Association. Circulation 2003;107:499-511.

\section{RevMan 2014 [Computer program]}

The Nordic Cochrane Centre, The Cochrane Collaboration Review Manager (RevMan). Version 5.3. Copenhagen: The Nordic Cochrane Centre, The Cochrane Collaboration, 2014.

\section{Shimizu 1985}

Shimizu A, Yano T, Saito Y, Inada Y. Isolation of an inhibitor of platelet aggregation from a fungus, Ganoderma lucidum. Pharmaceutical Bulletin 1985;33(7):3012-5.

\section{Tao 1990}

Tao J, Feng K-Y. Experimental and clinical studies on inhibitory effect of Ganoderma lucidum on platelet aggregation. Journal of Tongji Medical University 1990;10(4):240-3.

\section{CHARACTERISTICS OF STUDIES}

Characteristics of included studies [ordered by study ID]

\section{Teow 1996}

Teow S. Effective dosage of the extract of Ganoderma lucidum in the treatment of various ailments. In: Royse DJ, editors(s). Mushroom Biology and Mushroom Products. Pennsylvania: Pennsylvania State University, 1996.

\section{Tomoda 1986}

Tomoda M, Gonda R, Kasahara Y, Hikino H. Glycan structures of ganoderans B and C, hypoglycemic glycans of Ganoderma lucidum fruit bodies. Phytochemistry 1986;25(12):2817-20.

\section{Wachtel-Galor 2004a}

Wachtel-Galor S, Tomlinson B, Benzie I. Ganoderma lucidum ('Lingzhi'), a Chinese medicinal mushroom: biomarker responses in a controlled human supplementation. British Journal of Nutrition 2004;91(2):263-9.

\section{Wachtel-Galor 2004b}

Wachtel-Galor S, Szeto Y, Tomlinson B, Benzie I. Ganoderma lucidum ('Lingzhi'): acute and short term biomarker response to supplementation. International Journal of Food Sciences and Nutrition 2004;55(1):75-83.

\section{WHO 2011}

World Health Organization (WHO), World Heart Federation, World Stroke Organization: Mendis S, Puska P, Norving B, editors. Global atlas on cardiovascular disease prevention and control. Geneva: World Health Organisation, 2011.

\section{Willard 1990}

Willard, T. Reishi mushroom: Herb of spiritual potency and medical wonder. Issaquah, Washington: Sylvan Press, 1990.

\section{Yang 2002}

Yang B, Jeong S, Song C. Hypolipidemic effect of exo- and endo-biopolymers produced from submerged mycelial culture of Ganoderma lucidum in rats. Journal of Microbiology and Biotechnology 2002;12(6):872-7.

\section{Zhang 2004}

Zhang H, Lin Z. Hypoglycemic effect of Ganoderma lucidum polysaccharides. Acta Pharmacologica Sinica 2004;25(2):191-5.

Chu 2012

\section{Study characteristics}

\begin{tabular}{ll}
\hline Methods & Randomised controlled crossover trial of G lucidum vs placebo \\
\hline Participants & Inclusion criteria \\
- & Pre-hypertension or stage 1 hypertension (classified by JNC7; systolic BP $130-150$ mmHg or diastolic \\
& BP $85-100 \mathrm{mmHg}$ or being treated with antihypertensive \\
- & Mild to moderate elevation of plasma total cholesterol (total cholesterol $\geq 6.0$ mmol/L) and/or triglyc- \\
& eride $(\geq 1.7 \mathrm{mmol} / \mathrm{L}$ and $\leq 5.0$ mmol/L) with or without lipid lowering treatment. \\
- & Type 2 diabetes, but only well controlled (HbAlc $<8.5)$
\end{tabular}


Chu 2012 (Continued)

\section{Exclusion criteria}

- Recent cardiovascular events (last 6 months)

- Liver enzymes (> $2 x$ upper normal limit)

Setting was an outpatient clinic of teaching hospital (Prince of Wales Hospital, Hong Kong)

Interventions

G lucidum polysaccharide extract $1.44 \mathrm{~g} /$ day $(360 \mathrm{mg} /$ capsule) equal to $13.2 \mathrm{~g}$ of mushroom/day taken as 2 capsules twice/day

Duration was 12 weeks. Placebo and cross-over run in periods of 4 weeks

Intervention provided by Vita-Green Health Product Company Limited, Hong Kong

- Anthropometry
- BP
- Urine electrolytes
- Lipid profile
- Plasma glucose
- Apolipoprotein B
- Anti-oxidant enzymes
- Allantoin
- Uric acid
- Lymphocyte subsets
- Catecholamines
- Cortisol
- Cortisone

\section{Adverse events}

- Any side effect or change in activity or well-being

Notes

*Authors provided additional data for first stage of cross-over trial. Many variables had baseline values within normal ranges and were therefore not included in meta-analysis

\section{Risk of bias}

\begin{tabular}{lll}
\hline Bias & Authors' judgement & Support for judgement \\
\hline $\begin{array}{l}\text { Random sequence genera- } \\
\text { tion (selection bias) }\end{array}$ & Low risk & $\begin{array}{l}\text { Quote "This was a randomised, double-blind, cross-over study" } \\
\text { Authors were contacted and provided information that the randomisation se- } \\
\text { quence was conducted by personnel independent to the study using a com- } \\
\text { puter-generated program }\end{array}$
\end{tabular}

Allocation concealment Low risk (selection bias)

No information provided in the paper.

Authors were contacted and provided information that the randomisation sequence was conducted by personnel independent to the study using a computer-generated program. The interventions were "labelled ( $\mathrm{A}$ or $\mathrm{B}$ ) by external personnel. *

Incomplete outcome data Unclear risk (attrition bias)

All outcomes

\begin{abstract}
Quote "From twenty-six eligible subjects enrolled in the study, one withdrew due to personal reasons, one subject had poor compliance $(80 \%$ compliance from capsule counting) with therapy and one subject had intercurrent illness; so their data were not included in the per-protocol analysis". No intention-totreat analysis was performed. It is unclear whether the effect of missing data might induce clinically relevant bias in observed effect size
\end{abstract}


Chu 2012 (Continued)

${ }^{\star}$ Complete data could not be obtained from authors

Selective reporting (re- Unclear risk porting bias)

No primary outcome measure was specified. The authors aimed to determine whether the intervention had "...beneficial effects on a wide range of cardiovascular and metabolic parameters." There was an extensive description of outcome measures, but no protocol is available. Data were provided for all outcome measures described in the methods section. However some conclusions of treatment effect were made without between-group treatment effect sizes, though these can be determined from table data

Further data were provided by authors to measure between-group effects of the first stage only

\begin{tabular}{ll}
\hline Other bias & Low risk \\
& No funding issues apparent \\
\hline
\end{tabular}

$\begin{array}{ll}\begin{array}{l}\text { Blinding of participants } \\ \text { and personnel (perfor- }\end{array} & \text { Low risk } \\ \begin{array}{l}\text { Insufficient information provided in the paper. Authors were contacted and } \\ \text { pance bias) }\end{array} & \begin{array}{l}\text { provided information that placebo and intervention were identical and provid- } \\ \text { ed in bottles labelled (A or B) blindly at an external site }\end{array}\end{array}$

$\begin{array}{lll}\begin{array}{l}\text { Blinding of outcome as- } \\ \text { sessment (detection bias) }\end{array} & \text { Unclear risk } & \begin{array}{l}\text { No assessor blinding details are outlined. As most outcome measures are } \\ \text { pathology-based, outcome bias might not be greatly affected }\end{array}\end{array}$

Gao 2004a

\section{Study characteristics}

Methods Multi-centred randomised controlled trial of Ganopoly capsules versus placebo

\section{Participants}

\section{Inclusion criteria}

- Type II diabetes mellitus of $>3$ months' duration

- $>18$ years of age

- $\geq 8$ week interval between prior hypoglycaemic therapy and entry

- Body weight $90 \%-150 \%$ of desirable weight for sex, body frame and height

- Normal vital signs for age and disease state

- Normal ECG

- FPG 8.9-16.7 mmol/L in sulfonylurea-naïve patients

- FPG $<10 \mathrm{mmol} / \mathrm{L}$ before washout in sulfonylurea-treated patients

- Informed consent for participation

\section{Exclusion criteria}

- Used insulin within last 3 months

- Severe concurrent conditions

- Pregnancy or lactation

- Secondary diabetes mellitus

- People who had taken or were taking G lucidum preparations

Participants, baseline data presented as mean (SD) for intervention (GL) and control (C) groups

- Average age, years: I 57.2 (8.8); C 54.4 (8.1)

- Duration of disease, years: I 5.8 (3.5); C 6.3 (3.8)

- BMI: 29.8 (5.1); C 30.2 (5.2) 
Gao 2004a (Continued)

Interventions

Intervention: Ganopoly capsules each containing $600 \mathrm{mg}$ extract of G lucidum, with $25 \%$ (w/w) crude polysaccharides, equivalent to $9 \mathrm{~g}$ of fruiting body of $\mathrm{G}$ lucidum (provided by Encore International Co. Auckland, NZ). Dose: $5400 \mathrm{mg}$ per day (9 capsules), dose adjusted within first 4 weeks. 3 capsules taken orally, 3 times/day before meals for 12 weeks

Control: placebo (provided by Encore International, Auckland, NZ)

\begin{tabular}{|c|c|}
\hline Outcomes & $\begin{array}{l}\text { - HbAlc } \\
\text { - FPG } \\
\text { - PPG } \\
\text { - Triglycerides } \\
\text { - Total cholesterol } \\
\text { - HDL cholesterol } \\
\text { - LDL cholesterol } \\
\text { - Insulin } \\
\text { - C-peptide } \\
\text { - Body weight } \\
\text { - BP } \\
\text { - Concomitant medication or illness } \\
\text { - Clinical chemistry } \\
\text { - Haematological profile } \\
\text { - Lipid profile } \\
\text { - Urinalysis } \\
\text { - Serum testosterone } \\
\text { - Pregnancy } \\
\text { - Adverse events, categorised as events reported before treatment that were exacerbated during treat- } \\
\text { - } \text { ment; during treatment; or within } 7 \text { days after the study drug was stopped } \\
\text { - hazard to the patient, i.e. was fatal, life threatening, permanently disabling or required hospitalisation } \\
\text { - Hypoglycaemic events (recorded separately to adverse events); reports of symptoms actively solicited } \\
\text { at visits. Recorded as hypoglycaemia, even if confirmatory blood glucose tests were not performed. } \\
\text { Mild to moderate hypoglylcaemia: sweating, strong hunger, dizziness, tremors or blood glucose value } \\
\text { < } 2.5 \text { mmol/L. Severe hypoglycaemia: severely impaired consciousness that required the assistance } \\
\text { of another person and hospitalisation }\end{array}$ \\
\hline
\end{tabular}

Notes

Did not report data suitable for use in between-group comparisons in Review Manager 5. Authors did not respond to requests for additional information

\section{Risk of bias}

\section{Bias}

Random sequence genera- Unclear risk tion (selection bias)

\section{Authors' judgement Support for judgement}

No information. Quote ". . eligible patients were randomly assigned"

Insufficient information about sequence generation process to permit judgement of 'low' or 'high' risk of bias

\begin{tabular}{|c|c|c|}
\hline $\begin{array}{l}\text { Allocation concealment } \\
\text { (selection bias) }\end{array}$ & Unclear risk & $\begin{array}{l}\text { Insufficient information about the sequence generation process to permit } \\
\text { judgement of 'low' or 'high risk of bias' }\end{array}$ \\
\hline
\end{tabular}

Incomplete outcome data Unclear risk (attrition bias)

There were 71 participants: 8 were lost to follow-up but it was not stated which group they had been in and they were not included in the analysis. There is no indication that the analysis was by intention-to-treat. Quote "Changes between baseline and the last treatment were evaluated for all efficacy variables with the last observation carried forward... only patients with baseline and post baseline data were included in the primary analysis". This seems to de-

All outcomes 
Gao 2004a (Continued)

scribe how missing data was handled, but that the data of participants who dropped- out was not included

Overall it appears the data for drop-outs was not included and it is not known which group the 8 people were in There is a potential risk of bias due to incomplete outcome data

Insufficient reporting of attrition/exclusions to permit judgement of 'low' or 'high risk of bias'

Selective reporting (re- High risk porting bias)

No primary outcome measure specified. There is an overall unclear strategy for analysis

Quote: "... decreased the mean HbA1C from $8.4 \%$ to $7.6 \%$ at 12 weeks", but this indicates a within-group difference was their primary focus. The between-group difference might be roughly determined from Figure 1 . There was selective reporting, as baseline for FPG and PPG were provided but only PPG had post-treatment mean reported; both these can be regarded as within-group differences. Basic data for adverse events was provided for the intervention group only

For between group differences significance was found for PPG but data were not provided

Quote "Changes in fasting insulin, 2-hour postprandial insulin. .. were consistent; the between group differences in these end points were significant at the last visit." This is ambiguous. Also the mean total cholesterol, HDL and LDL and triglyceride values were not significantly decreased and there were no significant group differences. Again no data were provided

Overall, the primary outcomes were not specified, descriptions of statistical significance between groups were vague and no data were provided. No effect sizes could be determined due to no provision of control group means or between-group means. There was a high risk of bias due to selective outcome reporting

\begin{tabular}{ll}
\hline Other bias & Now risk \\
& Dose adjustment acceptable process \\
& No funding issues apparent \\
& The study appears to be free of other sources of bias
\end{tabular}

Blinding of participants and personnel (performance bias)
Unclear risk

It was stated that placebo was used as $1800 \mathrm{mg}$ three times daily for 12 weeks. No participant, or study personnel blinding details were outlined

With placebo statements, it could be implied that participants were blinded. However it is unclear whether study personnel were blinded, as considerable dosage adjustment was carried out. If study personnel were blinded this could affect implementation of the intervention and introduce performance bias
Blinding of outcome as- Unclear risk No assessor blinding details are outlined. As most outcome measures are sessment (detection bias) pathology-based, outcome bias might not be greatly affected

\section{Study characteristics}


Gao 2004b (Continued)

Methods Randomised controlled trial of Ganopoly capsules versus placebo

Participants

\section{Inclusion criteria}

- Men and women 18-75 years of age

- Coronary heart disease, confirmed by a comprehensive medical and physical examination including history, blood biochemistry and heart ultrasound scanning.

\section{Exclusion criteria}

- Severe disease of another vital organ

- Clinically significant haematologic, hepatic, metabolic, renal, rheumatologic, neurological or psychiatric disease

- Anaphylactic reactions

- Clinically significant cardiac or cardiovascular anomalies other than coronary heart disease

- Chronic obstructive pulmonary disease

- Abnormal carbon monoxide diffusion capacity

- Organ grafts

- Severe or disabling illnesses

- Systemic bacterial or fungal infection

- Clinically significant bleeding disorders

- Evidence of malignant neoplastic disease within 5 years

- Average daily intake of alcohol exceeding $50 \mathrm{~g}$ of ethanol

- Drug abuse within the previous year

Participants, baseline data presented as mean (SD) for intervention (GL) and control (C) groups unless indicated otherwise:

- Average age, years: GL 54.2 (9.8); C 55.4 (11.1)

- Duration of disease, years: GL 5.2 (1.5); C 5.5 (1.7)

- Cholesterol, xULN: GL 2.1 (1.2); C 2.2 (1.1)

- Systolic BP, mmHg: GL 142.5 (13.2); C 141.4 (14.2)

- Diastolic BP, mmHg: GL 96.4 (7.2); C 94.3 (8.9)

- > $50 \%$ narrowing of one major coronary artery, number: GL 28; C 25

- ECG abnormality, \%:GL 74; C 76
Intervention: Ganopoly capsules each containing $600 \mathrm{mg}$ extract of $\mathrm{G}$ lucidum, with $25 \%$ (w/w) crude polysaccharides, equivalent to $9 \mathrm{~g}$ fruiting body of $\mathrm{G}$ lucidum (provided by Encore International Co. Auckland, NZ). Dose: $5400 \mathrm{mg} /$ day (9 capsules), dose adjusted within first 4 weeks. 3 capsules taken orally, 3 times per day before meals for 12 weeks

Control: placebo (provided by Encore International, Auckland, NZ)

\begin{tabular}{ll}
\hline Outcomes & Body weight \\
- BP & - Concomitant medication or illness \\
- Clinical chemistry \\
- Haematological profile \\
- Triglycerides \\
- Total cholesterol \\
- HDL cholesterol \\
- LDL cholesterol \\
- Urinalysis \\
- ECG changes \\
- Vital symptoms and signs, graded as -lack, +minor (1-2 symptoms without impact on work and life), \\
\\
+++ mild (3-5 symptoms, some impact on life and work), and +++severe (>5 symptoms, stop work)
\end{tabular}


Gao 2004b (Continued)

- Adverse events, categorised as events reported before treatment that were exacerbated during treatment; during treatment; or within 7 days after the study drug was stopped

- Serious adverse event: any event, whether treatment-related or not, that posed a medically significant hazard to the participant, i.e. was fatal, life threatening, permanently disabling or required hospitalisation

Notes

Did not report data suitable for use in between-group comparisons in Review Manager 5. Authors did not respond to requests for additional information

\section{Risk of bias}

Bias Authors' judgement Support for judgement

Random sequence genera- Unclear risk tion (selection bias)

No information. Quote ". . e eligible patients were randomly assigned"

Insufficient information about the sequence generation process to permit judgement of 'low' or 'high risk of bias'

$\begin{array}{ll}\begin{array}{l}\text { Allocation concealment } \\ \text { (selection bias) }\end{array} & \text { Unclear risk } \\ \end{array}$

Incomplete outcome data Unclear risk
(attrition bias)

All outcomes

\begin{abstract}
There were 170 participants, 10 were lost to follow-up but they were not included in the analysis. 8 out of 10 were in the intervention group, which indicated that the drop-out may have been relevant to the treatment. There was no indication analysis was by intention-to-treat. Quote "Changes between baseline and the last treatment were evaluated for all efficacy variables with the last observation carried forward". This seems to describe how missing data was handled, but that the data for participants who dropped-out was not included
\end{abstract}

Overall it appears the data of drop-outs has not been included, and this may affect the assessment of effect and safety of intervention therapy. There is a potential risk of bias due to incomplete outcome data

Insufficient information to permit judgement of 'low' or 'high risk of bias'

Selective reporting (re- High risk
porting bias)

No primary outcome measure specified. The overall strategy for analysis was unclear.

There was selective reporting as baseline for BP and cholesterol level are provided, but only BP of intervention group has post-treatment mean result. Both may be regarded as within-group differences. Basic data for adverse events were provided for the intervention group only

For between-group differences significance was found for symptom and electrocardiographic improvement but standard deviation of data was not provided

Overall, the primary outcomes were not specified, descriptions of statistical significance between groups were vague and insufficient data were provided. No effect sizes could be determined due to no provision of control group means or between-group standard deviations. There was a high risk of bias due to selective outcome reporting

Other bias Low risk None noted

No funding issues apparent

The study appears to be free of other sources of bias 
Gao 2004b (Continued)

Blinding of participants and personnel (performance bias)
Unclear risk

Quote "This double blind...." It is stated that $1800 \mathrm{mg}$ of placebo were taken three times daily for 12 weeks. No participant, or study personnel blinding details were outlined.

With placebo statements, it could be implied that participants were blinded. However there is insufficient information to permit judgement of 'low' or 'high risk of bias'
Blinding of outcome as- Unclear risk sessment (detection bias)
Insufficient information to permit judgement of 'low' or 'high risk of bias'

\section{Klupp 2014}

\section{Study characteristics}

\section{Methods}

Participants

Randomised controlled trial of G lucidum, or G lucidum plus Cordyceps sinensis capsules, versus placebo

\section{Inclusion criteria}

- At least 18 years of age

- Able to provide informed consent in English

- Have high fasting serum glucose $\geq 6.1 \mathrm{mmol} / \mathrm{L}$

- Meet the diagnostic criteria for National Cholesterol Education Program Adult Treatment Panel III (NCEPATPIII) for metabolic syndrome. Therefore, in addition to the high fasting glucose participants must have at least two of the following:

- waist circumference $>102 \mathrm{~cm}$ (men) $/ 88 \mathrm{~cm}$ (women)

- fasting serum triglycerides $\geq 1.7 \mathrm{mmol} / \mathrm{L}$

- $H D L$ cholesterol $<1 \mathrm{mmol} / \mathrm{L}(\mathrm{men}) / 1.3 \mathrm{mmol} / \mathrm{L}$ (women)

- $B P \geq 130 / 85 \mathrm{mmHg}$

\section{Exclusion criteria}

- A known allergy to mushrooms

- Had taken G lucidum or $C$ sinensis in the past 12 months

- Pregnant or breastfeeding

- Any medical or social condition or circumstance that might prevent completion or compliance with the requirements of this trial

- Any significant active medical or psychiatric condition that the medical practitioner deemed made the person unsuitable for involvement in this trial e.g. malignancy, heart disease

- Significant renal impairment (serum creatinine $>160 \mathrm{mmol} / \mathrm{L}$ )

- Active hepatobiliary conditions including hepatitis ( $A, B$ or $C$ ); significant hepatic impairment (bilirubin > $30 \mathrm{mmol} / \mathrm{L}$, serum ALT (alanine aminotransferase) or AST (aspartate aminotransferase) > $1.5 x$ the upper limit of normal)

- Had major surgery in the past month or expecting surgery during the trial

- Had an organ transplant

- History of abnormal haemorrhaging or had taken an anti-coagulant in the last three months

- Currently using insulin treatment, or had done so in the past three months

- Any other active medical condition that might significantly interfere with glucose levels, such as systemic infection (e.g. tuberculosis, hepatitis, chronic sinusitis or any chronic sepsis)

- Recent history (3 months) of hypoglycaemic events

Participants, baseline data presented as mean (SD) for intervention (I) and control (C) groups

Average age, years: I 60.2 (0); C 57.1 (8.3) 
Klupp 2014 (Continued)

Duration of disease, years: I 7.1 (5.7); C 6.4 (5.2)

FPG, $\mathrm{mmol} / \mathrm{L}:$ I 8.7 (2.9); C 8.4 (2.7)

HbA1c, \%: I 7.7 (1.6); C 7.4 (1.4)

Triglycerides, mmol/L: I 2.52 (2.79); C 2.25 (0.94)

Systolic BP, mmHg: I 139 (17); C 135 (16)

Diastolic BP, mmHg: I 82 (10); C 82 (11)

BMI, $\mathrm{kg} / \mathrm{m}^{2}: \mathrm{I} 3401$ (6.8); C 34.3 (7.4)

Interventions

Intervention: G lucidum capsule (containing $372 \mathrm{mg}$ G lucidum mushroom extract), and G lucidum with C sinensis capsules (containing $375 \mathrm{mg}$ G lucidum mushroom extract and $125 \mathrm{mg} C$ sinensis extract). Mushroom extract refers to a concentrated form of nutrients derived from raw mushrooms, and spores, which have different but condensed amounts of nutrients, act as the 'seeds' of the fungus for dispersal purposes.

Dose: participants took capsules equalling approximately $4 \mathrm{~g} /$ day of either $\mathrm{G}$ lucidum, or $\mathrm{G}$ lucidum with $\mathrm{C}$ sinensis or placebo Participants were required to take 4 capsules twice daily, with food, for 16 weeks duration

Control: placebo (provided by GMP Pharmaceuticals)

Primary outcome
- Fasting blood glucose
- HbAlC
Secondary outcome
- For improving the other four diagnostic criteria of metabolic syndrome:
$\circ$ systolic and diastolic BP
$\circ$ triglycerides
$\circ$ waist circumference
$\circ$ hip circumference (secondary non-NCEP measure)
$\circ$ BMI (secondary non-NCEP measure)
$\circ$ HDL
For quality of life:
$\circ$ Short Form-36: Standard Version 2 Australian language

For high sensitivity C-reactive protein
$\circ$ total cholesterol
$\circ$ LDL
$\circ$ apolipoprotein A
$\circ$ apolipoprotein B
$\circ$ adverse effects

Notes

Data were collected at baseline and weeks 8 and 16 during intervention period. Follow-up data was also collected at week 24 after 8 weeks washout from intervention

\section{Risk of bias}

\section{Bias}

Authors' judgement Support for judgement

Random sequence genera- Low risk tion (selection bias)
Quote "These treatment sequences will be generated by Microsoft Excel computer randomisation strategies." 
Klupp 2014 (Continued)

Allocation concealment Low risk Quote "Randomisation will be organised by a single research officer of the (selection bias)

Centre for Complementary Medicine Research, but this process will be conducted completely external and unknown to the research team members listed in this protocol."

$\begin{array}{ll}\begin{array}{l}\text { Incomplete outcome data } \\ \text { (attrition bias) }\end{array} & \text { Low risk } \\ \text { All outcomes } & \begin{array}{l}86 \text { participants were allocated to } 3 \text { groups and } 9 \text { withdrew from the study. } \\ \text { However intention-to-treat analysis was used so that all participants were } \\ \text { analysed according to the group to which they were randomised }\end{array}\end{array}$

Selective reporting (re- Low risk
analysed according to the group to which they were randomised

porting bias) provided in the unpublished report

\begin{tabular}{|c|c|c|}
\hline Other bias & Low risk & $\begin{array}{l}\text { The research was partly financially supported by a pharmaceutical company } \\
\text { No other potential bias was noted }\end{array}$ \\
\hline $\begin{array}{l}\text { Blinding of participants } \\
\text { and personnel (perfor- } \\
\text { mance bias) }\end{array}$ & Low risk & $\begin{array}{l}\text { Quote "The treatment sequence code will be stored in two separate locked } \\
\text { and protected locations and these codes will be used to label pre-prepared } \\
\text { participant numbered medication containers. ...There is no need for compar- } \\
\text { isons between intervention capsules either by the researchers or the partici- } \\
\text { pants. However, the interventions of Ganoderma lucidum, Ganoderma lucidum } \\
\text { with Cordyceps sinensis and placebo will be indistinguishable in colour, smell, } \\
\text { taste, size and weight." Participants were surveyed at each stage of data collec- } \\
\text { tion about which medication they thought they were taking. The ratio of total } \\
\text { correct answers to total incorrect answers was } 1: 3\end{array}$ \\
\hline
\end{tabular}

$\begin{array}{ll}\begin{array}{l}\text { Blinding of outcome as- } \\ \text { sessment (detection bias) }\end{array} \quad \text { Low risk } & \begin{array}{l}\text { Quote "Due to the use of pre-randomised packaging and the nature of the in- } \\ \text { tervention, the participants, the assessors, the therapists and the data ana- } \\ \text { lysts will all remain blinded for the duration of the trial." }\end{array}\end{array}$

Wang 2008

\title{
Study characteristics
}

\begin{tabular}{ll}
\hline Methods & Randomised controlled trial of Ganopoly capsules versus placebo \\
\hline Participants & Inclusion criteria
\end{tabular}

\begin{abstract}
Inclusion criteria
50 outpatients with type 2 diabetes who had received an 8-week diet control and an exercise advice and whose blood glucose level was still maintained at $150 \mathrm{mg} / \mathrm{dL}-250 \mathrm{mg} / \mathrm{dL}$
\end{abstract}

\section{Exclusion criteria}

Liver, kidney or gastrointestinal dysfunction

\section{Participants, baseline data presented as mean (SD) for intervention (I) and control (C) groups:}

Average age, years: I 58.6 (2.3); C 61.8 (2.4)

Duration of disease, years: I $6.5(0.8) ;$ C $8.5(0.8)$

BMI, $\mathrm{kg} / \mathrm{m}^{2}:$ I 26.5 (1.0); C $25.3(0.7)$

Systolic BP, mmHg: I 127.3 (2.9); C 131.1 (2.6)

Diastolic BP, mmHg: I 74.2 (2.0); C 75.6 (1.9)

FPG, mg/dL: I 180.1 (6.5); C 184.7 (3.2) 
Wang 2008 (Continued)

$$
\begin{aligned}
& \text { 2hPPG, mg/dL: I } 282.9 \text { (8.5); C } 264.6 \text { (4.7) } \\
& \text { HbA1c, \%: I } 8.2 \text { (1.3); C } 8.5 \text { (1.4) }
\end{aligned}
$$

Interventions

Intervention: lingzhi was produced by the Guo-Ren-Shun-Tian-Tang Pharmaceutical Company. Lingzhi came from Nantou County Puli Town. The strain was authenticated by the Food Industry Research and Development Institute (FIRDI). Raw mushroom was made into powder through decoction, concentration, drying and then into capsules after quantity and quality approval. Dose: $1000 \mathrm{mg} 3$ times daily for 12 weeks

Control: placebos were prepared by Guo-Ren-Shun-Tian-Tang Pharmaceutical Company as well; these consisted of starch and had the same appearance as the lingzhi capsules

Additional treatments: prior co-comitant hypoglycaemic agents were maintained through the study in both groups

\begin{tabular}{ll}
\hline Outcomes & Fasting blood glucose \\
- & HbAlc \\
- & $2 \mathrm{hPPG}$ \\
- & Plasma glucose under the curve at $4^{\text {th }}$ hour of meal tolerance test
\end{tabular}

\section{Meal tolerance test}

Participants were given nutritional advice for 2 days' diet of $30 \mathrm{Kcal} / \mathrm{kg} / \mathrm{day}$. On the day of receiving the meal tolerance test, participants had a fasting blood test and were then provided with breakfast containing $1 / 5$ of the whole day's energy intake, comprising $55 \%$ carbohydrate, $30 \%$ fat and $15 \%$ protein. Blood was taken $1 \mathrm{~h}, 2 \mathrm{~h}, 3 \mathrm{~h}$ and $4 \mathrm{~h}$ after the breakfast to test blood glucose levels and calculate plasma glucose under the curve

Notes Reported that the endpoint mean of the placebo group was 187.9 (49) $\mathrm{mg} / \mathrm{dL}$. Our comparisons and calculations suggest this standard deviation value was not $49 \mathrm{mg} / \mathrm{dL}$, but rather, $4.9 \mathrm{mg} / \mathrm{dL}$

\begin{tabular}{|c|c|c|}
\hline Bias & Authors' judgement & Support for judgement \\
\hline $\begin{array}{l}\text { Random sequence genera- } \\
\text { tion (selection bias) }\end{array}$ & Unclear risk & $\begin{array}{l}\text { Insufficient information provided. Quote ". . eligible patients were randomly } \\
\text { assigned" }\end{array}$ \\
\hline $\begin{array}{l}\text { Allocation concealment } \\
\text { (selection bias) }\end{array}$ & Unclear risk & Insufficient information provided \\
\hline \multirow[t]{2}{*}{$\begin{array}{l}\text { Incomplete outcome data } \\
\text { (attrition bias) } \\
\text { All outcomes }\end{array}$} & Unclear risk & $\begin{array}{l}\text { There were } 50 \text { participants, it is not certain that the } 4 \text { withdrawals occurred } \\
\text { prior to randomisation. The wording that " } 46 \text { were allocated" sounds as if ran- } \\
\text { dom allocation occurred for only these participants, but it could mean that } \\
\text { they had already been allocated }\end{array}$ \\
\hline & & $\begin{array}{l}\text { Insufficient reporting of attrition/exclusions to permit judgement of 'low' or } \\
\text { 'high risk of bias' }\end{array}$ \\
\hline $\begin{array}{l}\text { Selective reporting (re- } \\
\text { porting bias) }\end{array}$ & Unclear risk & $\begin{array}{l}\text { Primary outcome measures were not clearly specified but could be inferred as } \\
\text { FPG, HbA1c, glucose area under-the-curve and } 2 \mathrm{~h} \text { PPG. Without access to the } \\
\text { protocol it is unclear whether these have been selected from a larger number } \\
\text { of outcomes e.g. plasma glucose under the curve at } 1^{\text {st }}, 2^{\text {nd }} \text {, and } 3^{\text {rd }} \text { hour of } \\
\text { meal tolerance test were not reported in both groups. No aims were provided } \\
\text { regarding adverse events and only partial adverse event results appeared to } \\
\text { be provided. It is unclear whether these data are affected by reporting bias }\end{array}$ \\
\hline Other bias & Low risk & None noted \\
\hline
\end{tabular}

\section{Risk of bias}


Wang 2008 (Continued)

No funding issues apparent

\section{Blinding of participants} and personnel (perfor-

Unclear risk mance bias)
It was stated that placebo was used as $1000 \mathrm{mg}$ three times daily for 12 weeks. No participant or study personnel blinding details were outlined

With placebo statements, it could be implied that participants were blinded Insufficient information about the sequence generation process to permit judgement of 'low' or 'high risk of bias'

\section{Abbreviations}

PPG: post prandial glucose 2hPPG: 2-hour post prandial glucose

2hPC: 2-hour post prandial glucose

BMI: body mass index

BP: blood pressure

FPG: fasting plasma glucose

h: hour(s)

HbA1c: fasting and stimulated glycosylated haemoglobin

HDL: high density lipoprotein

LDL: low density lipoprotein

NCEP: National Cholesterol Education Program

w/w: weight to weight

ULN: upper limit of normal

Characteristics of excluded studies [ordered by study ID]

\begin{tabular}{ll}
\hline Study & Reason for exclusion \\
\hline Jin 1996 & Was not a randomised or controlled clinical trial \\
\hline Wachtel-Galor 2004 & Trial evaluated effects in healthy participants \\
\hline
\end{tabular}

DATA AND ANALYSES

\section{Comparison 1. Ganoderma versus placebo}

\begin{tabular}{lllll}
\hline Outcome or subgroup title & No. of studies & $\begin{array}{l}\text { No. of partici- } \\
\text { pants }\end{array}$ & Statistical method & Effect size \\
\hline $1.1 \mathrm{HbA1C}(\%)$ at 12 to 16 weeks & 2 & 130 & $\begin{array}{l}\text { Mean Difference (IV, Fixed, 95\% } \\
\mathrm{Cl})\end{array}$ & $-0.07[-0.57,0.42]$ \\
\hline $\begin{array}{l}1.2 \text { Total cholesterol (mmol/L) 12-16 } \\
\text { weeks }\end{array}$ & 2 & 107 & $\begin{array}{l}\text { Mean Difference (IV, Fixed, 95\% } \\
\mathrm{Cl})\end{array}$ & $-0.07[-0.57,0.43]$ \\
\hline $\begin{array}{l}1.3 \text { Low density lipoprotein (mmol/ } \\
\text { L) 12-16 weeks }\end{array}$ & 2 & 107 & $\begin{array}{l}\text { Mean Difference (IV, Fixed, 95\% } \\
\mathrm{Cl})\end{array}$ & $0.02[-0.41,0.45]$ \\
\hline
\end{tabular}




\begin{tabular}{lllll}
\hline Outcome or subgroup title & No. of studies & $\begin{array}{l}\text { No. of partici- } \\
\text { pants }\end{array}$ & Statistical method & Effect size \\
\hline 1.4 Body mass index 12-16 weeks & 2 & 107 & $\begin{array}{l}\text { Mean Difference (IV, Fixed, 95\% } \\
\text { Cl) }\end{array}$ & $-0.32[-2.67,2.03]$ \\
\hline
\end{tabular}

Analysis 1.1. Comparison 1: Ganoderma versus placebo, Outcome 1: HbA1c (\%) at 12 to 16 weeks

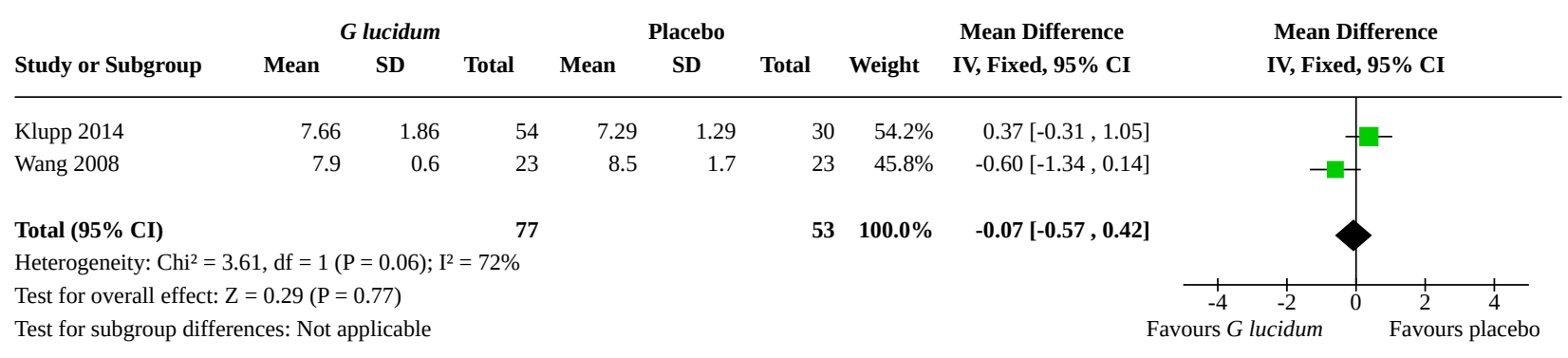

\section{Analysis 1.2. Comparison 1: Ganoderma versus placebo, Outcome 2: Total cholesterol (mmol/L) 12-16 weeks}

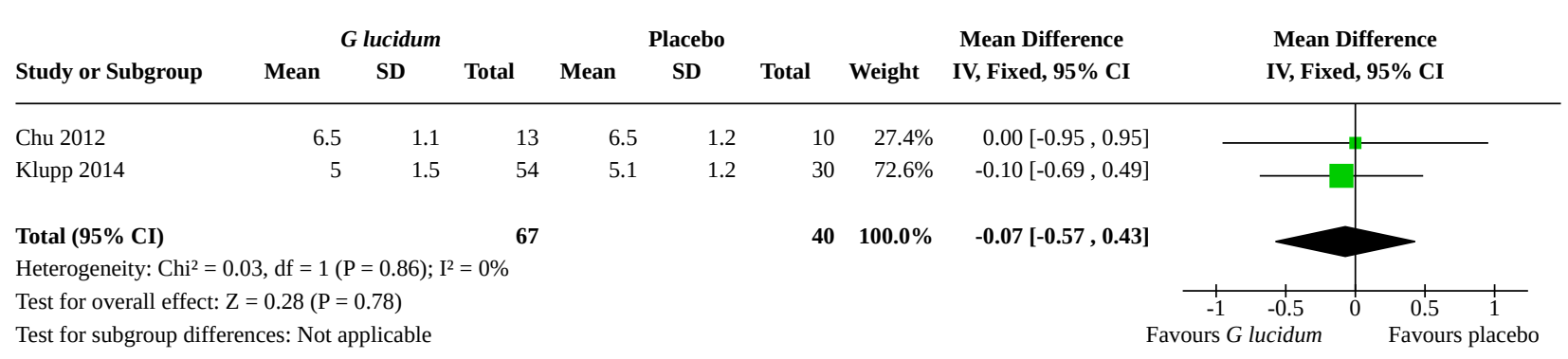

Analysis 1.3. Comparison 1: Ganoderma versus placebo, Outcome 3: Low density lipoprotein (mmol/L) 12-16 weeks

\begin{tabular}{|c|c|c|c|c|c|c|c|c|c|}
\hline \multirow[b]{2}{*}{ Study or Subgroup } & \multicolumn{3}{|c|}{ G lucidum } & \multicolumn{3}{|c|}{ Placebo } & \multicolumn{2}{|r|}{ Mean Difference } & \multirow{2}{*}{$\begin{array}{l}\text { Mean Difference } \\
\text { IV, Fixed, 95\% CI }\end{array}$} \\
\hline & Mean & SD & Total & Mean & SD & Total & Weight & IV, Fixed, 95\% CI & \\
\hline Chu 2012 & 4 & 1.1 & 13 & 3.9 & 1.2 & 10 & $20.2 \%$ & $0.10[-0.85,1.05]$ & \\
\hline Klupp 2014 & 2.8 & 1.2 & 54 & 2.8 & 1 & 30 & $79.8 \%$ & $0.00[-0.48,0.48]$ & \\
\hline Total $(95 \% \mathrm{CI})$ & & & 67 & & & 40 & $100.0 \%$ & $0.02[-0.41,0.45]$ & \\
\hline \multicolumn{10}{|c|}{ Heterogeneity: $\mathrm{Chi}^{2}=0.03, \mathrm{df}=1(\mathrm{P}=0.85) ; \mathrm{I}^{2}=0 \%$} \\
\hline \multirow{2}{*}{\multicolumn{4}{|c|}{$\begin{array}{l}\text { Test for overall effect: } \mathrm{Z}=0.09(\mathrm{P}=0.93) \\
\text { Test for subgroup differences: Not applicable }\end{array}$}} & & & & & +1 & -0.5 \\
\hline & & & & & & & & Favour & lucidum \\
\hline
\end{tabular}


Analysis 1.4. Comparison 1: Ganoderma versus placebo, Outcome 4: Body mass index 12-16 weeks

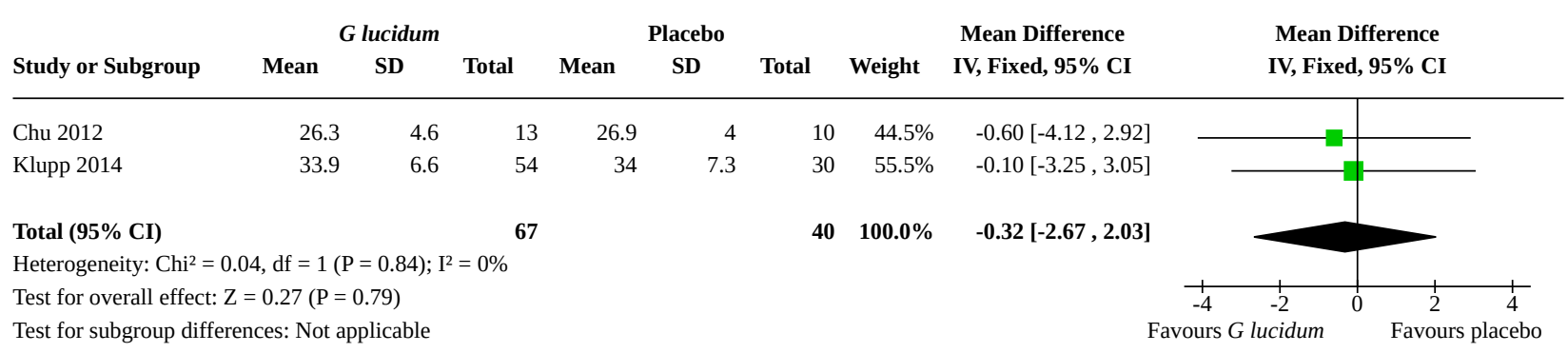




\begin{tabular}{|c|c|c|c|c|c|c|c|c|}
\hline \multirow{3}{*}{\multicolumn{2}{|c|}{ 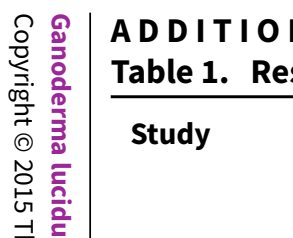 }} & $\begin{array}{l}\text { LE S } \\
\text { lyses co }\end{array}$ & cont & ta from onl & e stud & & & \\
\hline & & \multicolumn{3}{|c|}{ Experimental } & \multicolumn{3}{|c|}{ Control } & \multirow{2}{*}{$\begin{array}{l}\text { Mean difference } \\
\text { IV, Fixed, } 95 \% \mathrm{CI}\end{array}$} \\
\hline & & Mean & SD & Participants & Mean & SD & Participants & \\
\hline 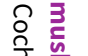 & \multicolumn{8}{|c|}{ 1.1 Fasting plasma glucose (mmol/L) 8 weeks } \\
\hline 尝 : & Klupp 2014 & 8.9 & 3.0 & 54 & 8.1 & 2.3 & 30 & $0.80[-0.35,1.95]$ \\
\hline & \multicolumn{8}{|c|}{ 1.2 Fasting plasma glucose $(\mathrm{mmol}) 16$ weeks } \\
\hline ำ & Klupp 2014 & 8.8 & 3.2 & 54 & 8.5 & 2.6 & 30 & $0.30[-0.95,1.55]$ \\
\hline & \multicolumn{8}{|c|}{ 1.3 Fasting plasma glucose $(\mathrm{mmol} / \mathrm{L}) 24$ weeks } \\
\hline 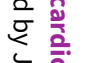 & Klupp 2014 & 9.0 & 3.6 & 54 & 8.0 & 1.9 & 30 & $1.00[-0.18,2.18]$ \\
\hline 它 & \multicolumn{8}{|c|}{$1.4 \mathrm{HbA} 1 \mathrm{C}(\%)$ at 8 weeks } \\
\hline 策 & Klupp 2014 & 7.5 & 1.6 & 54 & 7.2 & 1.3 & 30 & $0.30[-0.33,0.93]$ \\
\hline 党 & \multicolumn{8}{|c|}{$1.5 \mathrm{HbA} 1 \mathrm{C}(\%)$ at 24 weeks } \\
\hline 勇 & Klupp 2014 & 7.6 & 2.0 & 54 & 6.9 & 1.0 & 30 & $0.70[0.06,1.34]$ \\
\hline & \multicolumn{8}{|c|}{$1.62 \mathrm{hr}$ postprandial blood glucose $(\mathrm{mmol} / \mathrm{Ll}) 12$ weeks } \\
\hline & Wang 2008 & 16.3 & 0.8 & 23 & 15.6 & 0.6 & 23 & $0.70[0.29,1.11]$ \\
\hline & \multicolumn{8}{|c|}{ 1.7 Plasma glucose under the curve at $4^{\text {th }}$ hour of meal tolerance test $(\mathrm{mg} / \mathrm{dl} / \mathrm{h}) 12$ weeks } \\
\hline & Wang 2008 & 897.1 & 38.2 & 23 & 946.5 & 56.3 & 23 & $-49.40[-77.21,-21.59]$ \\
\hline & \multicolumn{8}{|c|}{ 1.8 Mean arterial pressure $(\mathrm{mmHg}) 8$ weeks } \\
\hline & Klupp 2014 & 98.0 & 9.9 & 54 & 96.1 & 99.0 & 30 & $1.90[-33.62,37.42]$ \\
\hline & \multicolumn{8}{|c|}{ 1.9 Mean arterial pressure $(\mathrm{mmHg}) 16$ weeks } \\
\hline & Klupp 2014 & 98.7 & 11.4 & 54 & 98.4 & 10.7 & 30 & $0.30[-4.59,5.19]$ \\
\hline & 1.10 Mean ar & are $(\mathrm{mmr}$ & eks & & & & & \\
\hline
\end{tabular}




\begin{tabular}{|c|c|c|c|c|c|c|c|}
\hline Klupp 2014 & 95.5 & 10.0 & 54 & 98.7 & 13.3 & 30 & $-3.20[-8.66,2.26]$ \\
\hline \multicolumn{8}{|c|}{ 1.11 Triglycerides $(\mathrm{mmol} / \mathrm{L}) 8$ weeks } \\
\hline Klupp 2014 & 2.0 & 0.9 & 54 & 2.1 & 0.8 & 30 & $-0.10[-0.47,0.27]$ \\
\hline \multicolumn{8}{|c|}{ 1.12 Triglycerides (mmol/L) 16 weeks } \\
\hline Klupp 2014 & 2.5 & 2.4 & 54 & 2.2 & 1.0 & 30 & $0.30[-0.43,1.03]$ \\
\hline \multicolumn{8}{|c|}{ 1.13 Triglycerides (mmol/L) 24 weeks } \\
\hline Klupp 2014 & 2.1 & 1.7 & 54 & 2.2 & 1.0 & 30 & $-0.10[-0.68,0.48]$ \\
\hline \multicolumn{8}{|c|}{ 1.14 Total cholesterol (mmol/L) 8 weeks } \\
\hline Klupp 2014 & 5.0 & 1.2 & 54 & 5.2 & 1.1 & 30 & $-0.20[-0.71,0.31]$ \\
\hline \multicolumn{8}{|c|}{ 1.15 Total cholesterol (mmol/L) 24 weeks } \\
\hline Klupp 2014 & 4.8 & 1.5 & 54 & 5.1 & 1.0 & 30 & $-0.30[-0.84,0.24]$ \\
\hline \multicolumn{8}{|c|}{ 1.16 High density lipoprotein (mmol/L) 8 weeks } \\
\hline Klupp 2014 & 1.2 & 0.5 & 54 & 1.1 & 0.2 & 30 & $0.10[-0.05,0.25]$ \\
\hline \multicolumn{8}{|c|}{ 1.17 High density lipoprotein (mmol/L)16 weeks } \\
\hline Klupp 2014 & 1.2 & 0.4 & 54 & 1.2 & 0.2 & 30 & $0.00[-0.13,0.13]$ \\
\hline \multicolumn{8}{|c|}{ 1.18 High density lipoprotein (mmol/L) 24 weeks } \\
\hline Klupp 2014 & 1.2 & 0.5 & 54 & 1.2 & 0.2 & 30 & $0.00[-0.15,0.15]$ \\
\hline \multicolumn{8}{|c|}{ 1.19 Low density lipoprotein (mmol/L) 8 weeks } \\
\hline Klupp 2014 & 3.0 & 1.1 & 54 & 2.9 & 1.1 & 30 & $0.10[-0.39,0.59]$ \\
\hline \multicolumn{8}{|c|}{ 1.20 Low density lipoprotein (mmol/L) 24 weeks } \\
\hline Klupp 2014 & 2.6 & 1.1 & 54 & 2.9 & 0.9 & 30 & $-0.30[-0.74,0.14]$ \\
\hline
\end{tabular}




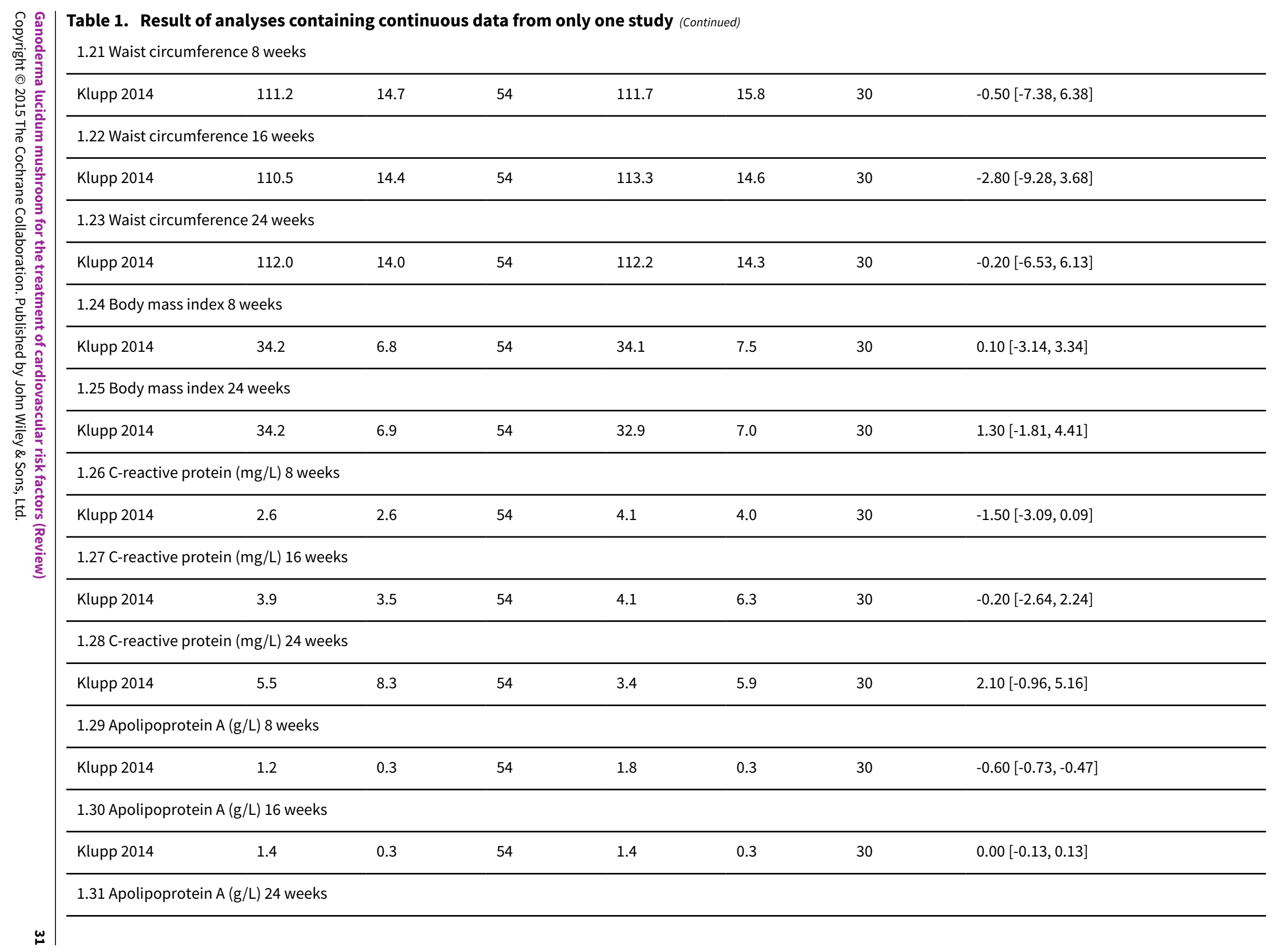




\begin{tabular}{|c|c|c|c|c|c|c|c|}
\hline Klupp 2014 & 1.2 & 0.3 & 54 & 1.8 & 0.3 & 30 & $-0.60[-0.73,-0.47]$ \\
\hline \multicolumn{8}{|c|}{ 1.32 Apolipoprotein B (g/L) 8 weeks } \\
\hline Klupp 2014 & 1.0 & 0.2 & 54 & 0.8 & 0.2 & 30 & $0.20[0.11,0.29]$ \\
\hline \multicolumn{8}{|c|}{ 1.33 Apolipoprotein B (g/L) 16 weeks } \\
\hline Klupp 2014 & 0.9 & 0.3 & 54 & 0.9 & 0.3 & 30 & $0.00[-0.13,0.13]$ \\
\hline \multicolumn{8}{|c|}{ 1.34 Apolipoprotein B (g/L) 24 weeks } \\
\hline Klupp 2014 & 1.1 & 0.2 & 54 & 1.1 & 0.3 & 30 & $0.00[-0.12,0.12]$ \\
\hline \multicolumn{8}{|c|}{1.35 Health related quality of life (physical summary) 8 weeks } \\
\hline Klupp 2014 & 45.3 & 8.9 & 54 & 47.85 & 6.14 & 30 & $-2.55[-5.78,0.68]$ \\
\hline \multicolumn{8}{|c|}{1.36 Health related quality of life (physical summary) 16 weeks } \\
\hline Klupp 2014 & 46.1 & 8.9 & 54 & 46.2 & 8.5 & 30 & $-0.10[-3.96,3.76]$ \\
\hline \multicolumn{8}{|c|}{1.37 Health related quality of life (physical summary) 24 weeks } \\
\hline Klupp 2014 & 46.4 & 9.4 & 54 & 46.2 & 8.6 & 30 & $0.20[-3.77,4.17]$ \\
\hline \multicolumn{8}{|c|}{1.38 Health related quality of life (mental summary) 8 weeks } \\
\hline Klupp 2014 & 49.23 & 11.5 & 54 & 49.3 & 10.0 & 30 & $-0.07[-4.78,4.64]$ \\
\hline \multicolumn{8}{|c|}{1.39 Health related quality of life (mental summary) 16 weeks } \\
\hline Klupp 2014 & 48.5 & 11.1 & 54 & 48.5 & 12.7 & 30 & $0.00[-5.42,5.42]$ \\
\hline \multicolumn{8}{|c|}{1.40 Health related quality of life (mental summary) 24 weeks } \\
\hline Klupp 2014 & 51.0 & 9.5 & 54 & 51.4 & 10.4 & 30 & $-0.40[-4.90,4.10]$ \\
\hline
\end{tabular}


Table 2. Results of analyses containing dichotomous data from only one study

\begin{tabular}{|c|c|c|c|c|c|}
\hline \multirow[t]{2}{*}{ Study } & \multicolumn{2}{|c|}{ Experimental } & \multicolumn{2}{|l|}{ Control } & \multirow{2}{*}{$\begin{array}{l}\text { Risk Ratio } \\
\text { Non-event; M-H, Fixed, } 95 \% \mathrm{CI}\end{array}$} \\
\hline & $\begin{array}{l}\text { Partici- } \\
\text { pants with } \\
\text { AE }\end{array}$ & $\begin{array}{l}\text { Total Par- } \\
\text { ticipants }\end{array}$ & $\begin{array}{l}\text { Partici- } \\
\text { pants with } \\
\text { AE }\end{array}$ & $\begin{array}{l}\text { Total Par- } \\
\text { ticipants }\end{array}$ & \\
\hline \multicolumn{6}{|c|}{ 2.1 Adverse events 0 to 16 weeks } \\
\hline Klupp 2014 & 24 & 54 & 8 & 30 & $1.67[0.86,3.24]$ \\
\hline \multicolumn{6}{|c|}{ 2.2 Adverse events (mild GI 0-16 weeks) } \\
\hline Klupp 2014 & 18 & 54 & 8 & 30 & $1.25[0.62,2.53]$ \\
\hline \multicolumn{6}{|c|}{ 2.3 Adverse events 16 - 24 weeks } \\
\hline Klupp 2014 & 10 & 54 & 1 & 30 & $1.11[1.42,2.95]$ \\
\hline \multicolumn{6}{|c|}{ 2.4 Adverse events (mild GI) 16 to 24 weeks } \\
\hline Klupp 2014 & 1 & 54 & 1 & 30 & $0.56[0.01,8.57]$ \\
\hline
\end{tabular}

\section{Abbreviation}

$\mathrm{AE}$ : adverse event(s)

\section{AP PENDICES}

\section{Appendix 1. Search strategies 2010 and 2011}

\section{CENTRAL}

\#1 MeSH descriptor Ganoderma explode all trees

\#2 ganoderma in All Text

\#3 Ling-Zhi in All Text

\#4 lingzhi in All Text

\#5 Reishi in All Text

\#6 (chinese in All Text near/6 mushroom* in All Text)

\#7 (medicinal ${ }^{\star}$ in All Text near/6 mushroom* in All Text)

$\# 8$ (\#1 or \#2 or \#3 or \#4 or \#5 or \#6)

\section{PubMed}

1. exp Ganoderma/

2. ganoderma*.tw.

3. Reishi.tw.

4. ling-zhi.tw.

5. lingzhi.tw.

6. (chinese adj5 mushroom\$).tw.

7. (medicinal\$ adj5 mushroom\$).tw.

8. reishus.tw.

9. mannentake.tw.

10. or/1-9

11. exp Cardiovascular Diseases/

12. heart ${ }^{\star}$. tw.

13. myocard ${ }^{*}$.tw.

14. cardio*.tw.

15. cardia*.tw. 
16. coronary ${ }^{\star} . \mathrm{tw}$.

17. pericard $^{\star}$.tw.

18. vascul*.tw.

19. (sick adj sinus).tw.

20. tachycardi*.tw.

21. (ventricular and fibrillat $\left.{ }^{\star}\right)$.tw.

22. (atrial and fibrillat ${ }^{\star}$ ).tw.

23. arrythmi*.tw.

24. endocardi ${ }^{\star} . t w$.

25. angina.tw.

26. thromboembolism*.tw.

27. thrombosis.tw.

28. ischem ${ }^{\star} . t w$.

29. ischaem*.tw.

30. Heart Injuries/

31. risk factors/

32. risk ${ }^{\star}$. tw.

33. (blood adj pressure ${ }^{\star}$ ).tw.

34. glucose.tw.

35. lipid*.tw.

36. cholesterol.tw.

37. exp Dyslipidemias/

38. exp lipoproteins/ or lipoproteins, hdl/

39. exp Glucose/

40. or/11-39

41.10 and 40

42. exp animals/ not humans.sh.

43. 41 not 42

\section{Science Direct}

\#1 TS=ganoderma

\#2 TS=Ling-zhi

\#3 TS=lingzhi

\#4 TS=Reishi

\#5 TS=Chinese $w / 6$ mushroom*

\#6 TS=medicinal $w / 6$ mushroom ${ }^{*}$

\#7 \#1 OR \#2 OR \#3 OR \#4 OR \#5 OR \#6

\#8 TS=heart*

\#9 TS=myocard ${ }^{\star}$

\#10 TS=cardio*

\#11 TS=cardia*

\#12 TS=coronary ${ }^{*}$

\#13 TS=pericard ${ }^{*}$

\#14 TS=vascul ${ }^{*}$

\#15 TS=sick adj sinus

\#16 TS=tachycardia*

\#17 TS=ventricular and fibrillate*

\#18 TS=atrial and fibrillate*

\#19 TS=arrythmi*

\#20 TS=endocardi ${ }^{*}$

\#21 TS=angina

\#22 TS=thromboembolism*

\#23 TS=thrombosis

\#24 TS=ischem*

\#25 TS=ischaem ${ }^{\star}$

\#26 TS=risk*

\#27 TS=blood adj pressure*

\#28 TS=glucose

\#29 TS=lipid*

\#30 TS=cholesterol

\#31 TS=heart injuries 
\#32 TS=Dyslipidemias

\#33 TS=Cardiovascular disease

\#34 \#8 OR \#9 OR \#10 OR \#11 OR \#12 OR \#13 OR \#14 OR \#15 OR \#16 OR \#17 OR \#18 \#19 OR \#20 OR \#21 OR \#22 OR \#23 OR \#24 OR \#25 OR \#26 OR \#27 OR \#28 OR \#29 OR \#30 OR \#31 OR \#32 OR \#33

\#35 \#7 AND \#34

\section{EMBASE}

1 exp ganoderma/

2 Ganoderma Lucidum Extract/

3 ganoderma.tw.

4 Reishi.tw.

5 ling-zhi.tw.

6 lingzhi.tw.

7 (chinese adj5 mushroom\$).tw.

8 (medicinal\$ adj5 mushroom\$).tw.

9 or/1-8

10 limit 9 to human

\section{Consult}

\#1 TS=ganoderma

\#2 TS=Ling-zhi

\#3 TS=lingzhi

\#4 TS=Reishi

\#5 TS=Chinese $w / 6$ mushroom *

\#6 TS=medicinal $w / 6$ mushroom *

\#7 \#1 OR \#2 OR \#3 OR \#4 OR \#5 OR \#6

\#8 TS=heart *

\#9 TS=myocard *

\#10 TS=cardio*

\#11 TS=cardia*

$\# 12 \mathrm{TS}=$ coronary $^{*}$

\#13 TS=pericard ${ }^{\star}$

\#14 TS=vascul *

\#15 TS=sick adj sinus

\#16 TS=tachycardia*

\#17 TS=ventricular and fibrillate*

$\# 18$ TS=atrial and fibrillate*

\#19 TS=arrythmi*

\#20 TS=endocardi *

\#21 TS=angina

\#22 TS=thromboembolism *

\#23 TS=thrombosis

\#24 TS=ischem*

\#25 TS=ischaem*

\#26 TS=risk*

\#27 TS=blood adj pressure ${ }^{\star}$

\#28 TS=glucose

\#29 TS=lipid*

\#30 TS=cholesterol

\#31 TS=heart injuries

\#32 TS=Dyslipidemias

\#33 TS=Cardiovascular disease

\#34 \#8 OR \#9 OR \#10 OR \#11 OR \#12 OR \#13 OR \#14 OR \#15 OR \#16 OR \#17 OR \#18 \#19 OR \#20 OR \#21 OR \#22 OR \#23 OR \#24 OR \#25 OR \#26 OR \#27 OR \#28 OR \#29 OR \#30 OR \#31 OR \#32 OR \#33

\#35 \#7 AND \#34

\section{Stat!Ref-Medical}

\#1 TS=ganoderma

\#2 TS=Ling-zhi

\#3 TS=lingzhi

\#4 TS=Reishi

Ganoderma lucidum mushroom for the treatment of cardiovascular risk factors (Review)

Copyright (C 2015 The Cochrane Collaboration. Published by John Wiley \& Sons, Ltd. 
\#5 TS=Chinese $w / 6$ mushroom ${ }^{*}$

\#6 TS=medicinal $\mathrm{w} / 6$ mushroom ${ }^{*}$

\#7 \#1 OR \#2 OR \#3 OR \#4 OR \#5 OR \#6

\#8 TS=heart *

\#9 TS=myocard ${ }^{*}$

\#10 TS=cardio*

\#11 TS=cardia*

$\# 12$ TS=coronary *

\#13 TS=pericard ${ }^{*}$

\#14 TS=vascul ${ }^{\star}$

\#15 TS=sick adj sinus

\#16 TS=tachycardia*

\#17 TS=ventricular and fibrillate*

\#18 TS=atrial and fibrillate*

\#19 TS=arrythmi*

\#20 TS=endocardi ${ }^{\star}$

\#21 TS=angina

\#22 TS=thromboembolism*

\#23 TS=thrombosis

\#24 TS=ischem *

\#25 TS=ischaem*

\#26 TS=risk *

\#27 TS=blood adj pressure*

\#28 TS=glucose

\#29 TS=lipid*

\#30 TS=cholesterol

\#31 TS=heart injuries

\#32 TS=Dyslipidemias

\#33 TS=Cardiovascular disease

\#34 \#8 OR \#9 OR \#10 OR \#11 OR \#12 OR \#13 OR \#14 OR \#15 OR \#16 OR \#17 OR \#18 \#19 OR \#20 OR \#21 OR \#22 OR \#23 OR \#24 OR \#25 OR \#26 OR \#27 OR \#28 OR \#29 OR \#30 OR \#31 OR \#32 OR \#33

\#35 \#7 AND \#34

\section{Biomed Central}

\#1 TS=ganoderma

\#2 TS=Ling-zhi

\#3 TS=lingzhi

\#4 TS=Reishi

\#5 TS=Chinese $\mathrm{w} / 6$ mushroom*

\#6 TS=medicinal $w / 6$ mushroom *

\#7 \#1 OR \#2 OR \#3 OR \#4 OR \#5 OR \#6

\#8 TS=heart ${ }^{*}$

\#9 TS=myocard ${ }^{*}$

\#10 TS=cardio*

\#11 TS=cardia*

\#12 TS=coronary *

\#13 TS=pericard*

\#14 TS=vascul ${ }^{\star}$

\#15 TS=sick adj sinus

\#16 TS=tachycardia*

\#17 TS=ventricular and fibrillate*

\#18 TS=atrial and fibrillate*

\#19 TS=arrythmi*

\#20 TS=endocardi *

\#21 TS=angina

\#22 TS=thromboembolism*

\#23 TS=thrombosis

\#24 TS=ischem*

\#25 TS=ischaem*

\#26 TS=risk*

\#27 TS=blood adj pressure* 
\#28 TS=glucose

\#29 TS=lipid*

\#30 TS=cholesterol

\#31 TS=heart injuries

\#32 TS=Dyslipidemias

\#33 TS=Cardiovascular disease

\#34 \#8 OR \#9 OR \#10 OR \#11 OR \#12 OR \#13 OR \#14 OR \#15 OR \#16 OR \#17 OR \#18 \#19 OR \#20 OR \#21 OR \#22 OR \#23 OR \#24 OR \#25 OR

\#26 OR \#27 OR \#28 OR \#29 OR \#30 OR \#31 OR \#32 OR \#33

\#35 \#7 AND \#34

\section{Scopus}

\#1 ganoderma as SCOPUS heading

\#2 ganoderma in All Fields

\#3 ling-Zhi in All Fields

\#4 lingzhi in All Fields

\#5 reishi in All Fields

\#6 chinese W/6 mushroom* in Advanced Search

\#7 medicinal ${ }^{*}$ W/6 mushroom ${ }^{*}$ in Advanced Search

\#8 ((ALL(ganoderma)) OR (ALL(ling-zhi)) OR (ALL(lingzhi)) OR (ALL(reishi)) OR (chinese W/6 mushroom) OR (medicinal* W/6 mushroom)) \#9 ((ALL(ganoderma)) OR (ALL(ling-zhi)) OR (ALL(lingzhi)) OR (ALL(reishi)) OR (chinese W/6 mushroom) OR (medicinal* W/6 mushroom)) AND cardiovascular

\#10 “clinical trial” in All Fields \#11 (ALL("clinical trial")) AND (((ALL(ganoderma)) OR (ALL(ling-zhi)) OR (ALL(lingzhi)) OR (ALL(reishi)) OR (chinese W/6 mushroom*) OR (medicinal W/6 mushroom*)) AND cardiovascular)

\section{CINAHL}

\#1 ganoderma as CINAHL heading

\#2 ganoderma in All Text

\#3 Ling-Zhi in All Text

\#4 Lingzhi in All Text

\#5 Reishi in All Text

\#6 Chinese $\mathrm{n} 6$ mushroom* in All Text

\#7 medicinal ${ }^{*}$ n6 mushroom* in All Text

\#8 (S1 or S2 or S3 or S4 or S5 or S6)

\section{Current content}

\#1 TS=ganoderma

\#2 TS=Ling-zhi

\#3 TS=lingzhi

\#4 TS=Reishi

\#5 TS=Chinese $w / 6$ mushroom *

\#6 TS=medicinal $\mathrm{w} / 6$ mushroom ${ }^{*}$

\#7 \#1 OR \#2 OR \#3 OR \#4 OR \#5 OR \#6

\#8 TS=heart *

\#9 TS=myocard ${ }^{\star}$

\#10 TS=cardio*

$\# 11$ TS=cardia*

\#12 TS=coronary*

\#13 TS=pericard ${ }^{\star}$

\#14 TS=vascul ${ }^{\star}$

\#15 TS=sick adj sinus

\#16 TS=tachycardia*

\#17 TS=ventricular and fibrillate*

\#18 TS=atrial and fibrillate*

\#19 TS=arrythmi*

\#20 TS=endocardi ${ }^{*}$

\#21 TS=angina

\#22 TS=thromboembolism*

\#23 TS=thrombosis

\#24 TS=ischem*

\#25 TS=ischaem *

\#26 TS=risk ${ }^{*}$ 
\#27 TS=blood adj pressure*

\#28 TS=glucose

\#29 TS=lipid*

\#30 TS=cholesterol

\#31 TS=heart injuries

\#32 TS=Dyslipidemias

\#33 TS=Cardiovascular disease

\#34 \#8 OR \#9 OR \#10 OR \#11 OR \#12 OR \#13 OR \#14 OR \#15 OR \#16 OR \#17 OR \#18 \#19 OR \#20 OR \#21 OR \#22 OR \#23 OR \#24 OR \#25 OR \#26 OR \#27 OR \#28 OR \#29 OR \#30 OR \#31 OR \#32 OR \#33

\#35 \#7 AND \#34

\section{Health and Medical Complete}

\#1 Citation\&Abstract =ganoderma

\#2 Citation\&Abstract $=$ Ling-zhi

\#3 Citation\&Abstract $=$ lingzhi

\#4 Citation\&Abstract $=$ Reishi

\#5 Citation\&Abstract $=$ Chinese $\mathrm{w} / 6$ mushroom $*$

\#6 Citation\&Abstract $=$ medicinal w/6 mushroom *

\#7 \#1 OR \#2 OR \#3 OR \#4 OR \#5 OR \#6

\#8 Citation\&Abstract $=$ heart $^{*}$

\#9 Citation\&Abstract $=$ myocard ${ }^{*}$

$\# 10$ Citation\&Abstract $=$ cardio $*$

\#11 Citation\&Abstract $=$ cardia $*$

\#12 Citation\&Abstract $=$ coronary ${ }^{*}$

\#13 Citation\&Abstract $=$ pericard ${ }^{\star}$

$\# 14$ Citation\&Abstract $=$ vascul $^{\star}$

$\# 15$ Citation\&Abstract $=$ sick adj sinus

\#16 Citation\&Abstract =tachycardia*

\#17 Citation\&Abstract = ventricular and fibrillate ${ }^{*}$

\#18 Citation\&Abstract $=$ atrial and fibrillate*

\#19 Citation\&Abstract $=$ arrythmi ${ }^{\star}$

\#20 Citation\&Abstract $=$ endocardi ${ }^{\star}$

\#21 Citation\&Abstract =angina

\#22 Citation\&Abstract =thromboembolism *

\#23 Citation\&Abstract =thrombosis

\#24 Citation\&Abstract =ischem*

\#25 Citation\&Abstract =ischaem *

\#26 Citation\&Abstract $=$ risk $^{*}$

\#27 Citation\&Abstract $=$ blood adj pressure ${ }^{\star}$

\#28 Citation\&Abstract $=$ glucose

\#29 Citation\&Abstract $=$ lipid $^{*}$

\#30 Citation\&Abstract $=$ cholesterol

\#31 Citation\&Abstract $=$ heart injuries

\#32 Citation\&Abstract $=$ Dyslipidemias

\#33 Citation\&Abstract $=$ Cardiovascular disease

\#34 \#8 OR \#9 OR \#10 OR \#11 OR \#12 OR \#13 OR \#14 OR \#15 OR \#16 OR \#17 OR \#18 \#19 OR \#20 OR \#21 OR \#22 OR \#23 OR \#24 OR \#25 OR \#26 OR \#27 OR \#28 OR \#29 OR \#30 OR \#31 OR \#32 OR \#33

\#35 \#7 AND \#34

\section{Science Citations Index}

1. exp Ganoderma/

2. ganoderma*.tw.

3. Reishi.tw.

4. ling-zhi.tw.

5. lingzhi.tw.

6. (chinese adj5 mushroom\$).tw.

7. (medicinal\$ adj5 mushroom\$).tw.

8. reishus.tw.

9. mannentake.tw.

10. or/1-9

11. exp Cardiovascular Diseases/ 
12. heart*.tw.

13. myocard $^{\star}$. tw.

14. cardio*.tw.

15. cardia*.tw.

16. coronary ${ }^{\star}$. tw.

17. pericard ${ }^{\star} . t w$.

18. vascul ${ }^{\star}$. tw.

19. (sick adj sinus).tw.

20. tachycardi ${ }^{\star}$.tw.

21. (ventricular and fibrillat*).tw.

22. (atrial and fibrillat*).tw.

23. arrythmi ${ }^{\star}$.tw.

24. endocardi ${ }^{\star}$. tw.

25. angina.tw.

26. thromboembolism ${ }^{\star}$.tw.

27. thrombosis.tw.

28. ischem ${ }^{\star}$. tw.

29. ischaem ${ }^{\star}$. tw.

30. Heart Injuries/

31. risk factors/

32. risk $^{\star}$. tw.

33. (blood adj pressure $\left.{ }^{\star}\right)$.tw.

34. glucose.tw.

35. lipid ${ }^{\star}$.tw.

36. cholesterol.tw.

37. exp Dyslipidemias/

38. exp lipoproteins/ or lipoproteins, hdl/

39. exp Glucose/

40. or/11-39

41. 10 and 40

42. exp animals/ not humans.sh.

\section{BIOSIS}

\#30 \#29 AND \#9

\#29 \#28 OR \#27 OR \#26 OR \#25 OR \#24 OR \#23 OR \#22 OR \#21 OR \#20 OR \#19 OR \#18 OR \#17 OR \#16 OR \#15 OR \#14 OR \#13 OR \#12 OR \#11 OR \#10

\#28 TS=(thrombosis OR thromboembolism*)

\#27 TS=(glucose OR lipid* OR cholesterol OR dyslipidemias OR lipoproteins)

\#26 TS=(blood SAME pressure*)

$\# 25$ TS=risk ${ }^{*}$

\#24 TS=(ischem* OR ischaem $\left.{ }^{\star}\right)$

\#23 TS=angina

\#22 TS=endocardi ${ }^{\star}$

\#21 TS=arrythmi*

\#20 TS=(atrial SAME fibrillat ${ }^{\star}$ )

\#19 TS=(ventricular SAME fibrillat ${ }^{\star}$ )

\#18 TS=tachycardi*

\#17 TS=(sick SAME sinus)

$\# 16$ TS=vascul ${ }^{\star}$

\#15 TS=pericard ${ }^{\star}$

\#14 TS=coronary*

$\# 13$ TS=cardia*

\#12 TS=cardio*

$\# 11 \mathrm{TS}=$ myocard $^{*}$

$\# 10 \mathrm{TS}=$ heart $^{*}$

\#9 \#8 OR \#7 OR \#6 OR \#5 OR \#4 OR \#3 OR \#2 OR \#1

\#8 TS=reishus

\#7 TS=mannentake

\#6 TS=(medicinal ${ }^{*}$ SAME mushroom* ${ }^{\star}$ )

\#5 TS=(chinese* SAME mushroom*)

\#4 TS=lingzhi 
\#3 TS=(ling zhi)

\#2 TS=reishi

\#1 TS=ganoderma*

\section{Current Controlled Trials}

\#1 Ganoderma

\#2 Ling-zhi

\#3 Lingzhi

\#4 Reishi

\#5 mushroom

\#1 OR \#2 OR \#3 OR \#4 OR \#5

\section{Australian New Zealand Clinical Trials Registry}

\#1 Ganoderma

\#2 Ling-zhi

\#3 Lingzhi

\#4 Reishi

\#5 mushroom

\#1 OR \#2 OR \#3 OR \#4 OR \#5

\section{CentreWatch Clinical Trials Listing Service}

\#1 Ganoderma

\#2 Ling-zhi

\#3 Lingzhi

\#4 Reishi

\#5 mushroom

\#1 OR \#2 OR \#3 OR \#4 OR \#5

\section{clinicaltrials.gov}

\#1 Ganoderma

\#2 Ling-zhi

\#3 Lingzhi

\#4 Reishi

\#5 mushroom

\#1 OR \#2 OR \#3 OR \#4 OR \#5

\section{Chinese Biomedical Literature Database}

1, [Keyword=Ling Zhi(Ganoderma Lucidum)]

2, [Keyword=Xin Xue Guan(cardiovascular) or Xin Zang(heart) or Xun Huan Xi Tong(circulation system) or Xue Ya(blood pressure) or Xue Tang (blood sugar) or Xue Zhi(blood lipid) or Fei Pang(obesity)]

(\#1 AND \#2)

\section{Chinese Medical Current Contents}

1, [Keyword=Ling Zhi(Ganoderma Lucidum)]

2, [Keyword=Xin Xue Guan(cardiovascular) or Xin Zang(heart) or Xun Huan Xi Tong(circulation system) or Xue Ya(blood pressure) or Xue Tang (blood sugar) or Xue Zhi(blood lipid) or Fei Pang(obesity)]

(\#1 AND \#2)

\section{China Network Knowledge Infrastructure}

1, [Keyword=Ling Zhi]

2, [Keyword=Xin Xue Guan(cardiovascular) or Xin Zang(heart) or Xun Huan Xi Tong(circulation system) or Xue Ya(blood pressure) or Xue Tang (blood sugar) or Xue Zhi(blood lipid) or Fei Pang(obesity)]

(\#1 AND \#2)

\section{VIP Database}

1, [Keyword=Ling Zhi]

2, [Keyword=Xin Xue Guan(cardiovascular) or Xin Zang(heart) or Xun Huan Xi Tong(circulation system) or Xue Ya(blood pressure) or Xue Tang (blood sugar) or Xue Zhi(blood lipid) or Fei Pang(obesity)]

(\#1 Pang(obesity)](\#1 AND \#2) 
Appendix 2. Search strategies 2013 and 2014

\section{CENTRAL}

\#1MeSH descriptor Ganoderma explode all trees

\#2ganoderma*

\#3Ling-Zhi

\#4lingzhi

\#5Reishi

\#6chinese near/6 mushroom ${ }^{\star}$

\#7medicinal ${ }^{\star}$ near/6 mushroom ${ }^{\star}$

\#8mannentake

\#9reishus

\#10(\#1 OR \#2 OR \#3 OR \#4 OR \#5 OR \#6 OR \#7 OR \#8 OR \#9)

\section{MEDLINE OVID}

1. exp Ganoderma/

2. ganoderma*.tw.

3. Reishi.tw.

4. ling-zhi.tw.

5. lingzhi.tw.

6. (chinese adj5 mushroom\$).tw.

7. (medicinal\$ adj5 mushroom\$).tw.

8. reishus.tw.

9. mannentake.tw.

10. or/1-9

11. exp Cardiovascular Diseases/

12. heart ${ }^{\star}$. tw.

13. myocard ${ }^{*}$.tw.

14. cardio*.tw.

15. cardia*.tw.

16. coronary $^{\star} . \mathrm{tw}$.

17. pericard ${ }^{\star} . t w$.

18. vascul*.tw.

19. (sick adj sinus).tw.

20. tachycardi*.tw.

21. (ventricular and fibrillat $\left.{ }^{\star}\right)$.tw.

22. (atrial and fibrillat ${ }^{\star}$ ).tw.

23. arrythmi*.tw.

24. endocardi ${ }^{\star}$. tw.

25. angina.tw.

26. thromboembolism*.tw.

27. thrombosis.tw.

28. ischem ${ }^{\star}$. tw.

29. ischaem*.tw.

30. Heart Injuries/

31. risk factors/

32. risk $^{\star}$. tw.

33. (blood adj pressure ${ }^{\star}$ ).tw.

34. glucose.tw.

35. lipid*.tw.

36. cholesterol.tw.

37. exp Dyslipidemias/

38. exp lipoproteins/ or lipoproteins, hdl/

39. exp Glucose/

40. or/11-39

41.10 and 40

42. exp animals/ not humans.sh.

43. 41 not 42

\section{EMBASE OVID}

1. exp ganoderma/ 
2. Ganoderma lucidum extract/

3. ganoderma*.tw.

4. Reishi.tw.

5. ling-zhi.tw.

6. lingzhi.tw.

7. (chinese adj5 mushroom\$).tw.

8. (medicinal\$ adj5 mushroom\$).tw.

9. mannentake.tw.

10. reishus.tw.

11. or/1-10

12. (animal/ or nonhuman/) not human/

13. 11 not 12

\section{CINAHL Plus with Full Text}

\section{S11 S9 AND S10}

S10 EM 20101001-20130426

$\mathrm{S} 9 \mathrm{~S} 1$ or $\mathrm{S} 2$ or $\mathrm{S} 3$ or $\mathrm{S} 4$ or $\mathrm{S} 5$ or $\mathrm{S} 6$ or $\mathrm{S} 7$ or $\mathrm{S} 8$

S8 TX reishus

S7 TX mannentake

S6 TX (medicinal* n $^{\text {mushroom*}}{ }^{\star}$ )

S5 TX (chinese n6 mushroom*)

S4 TX reishi

S3 TX lingzhi

S2 TX ling-zhi

S1 TX ganoderma

\section{Science Citation Index and Conference Proceedings Citation Index on Web of Science}

\#30 \#29 AND \#9

\#29 \#28 OR \#27 OR \#26 OR \#25 OR \#24 OR \#23 OR \#22 OR \#21 OR \#20 OR \#19 OR \#18 OR \#17 OR \#16 OR \#15 OR \#14 OR \#13 OR \#12 OR

$\# 11$ OR \#10

\#28 TS=(thrombosis OR thromboembolism*)

\#27 TS=(glucose OR lipid ${ }^{\star}$ OR cholesterol OR dyslipidemias OR lipoproteins)

\#26 TS=(blood SAME pressure ${ }^{\star}$ )

\#25 TS=risk ${ }^{*}$

\#24 TS=(ischem* OR ischaem $\left.{ }^{\star}\right)$

\#23 TS=angina

\#22 TS=endocardi ${ }^{*}$

\#21 TS=arrythmi*

\#20 TS=(atrial SAME fibrillat $\left.{ }^{\star}\right)$

\#19 TS=(ventricular SAME fibrillat* $)$

\#18 TS=tachycardi ${ }^{\star}$

$\# 17$ TS=(sick SAME sinus)

\#16 TS=vascul ${ }^{*}$

\#15 TS=pericard*

\#14 TS=coronary*

\#13 TS=cardia*

$\# 12$ TS=cardio*

\#11 TS=myocard*

\#10 TS=heart ${ }^{\star}$

\#9 \#8 OR \#7 OR \#6 OR \#5 OR \#4 OR \#3 OR \#2 OR \#1

\#8 TS=reishus

\#7 TS=mannentake

\#6 TS=(medicinal ${ }^{*}$ SAME mushroom $\left.{ }^{*}\right)$

\#5 TS=(chinese* SAME mushroom $\left.{ }^{\star}\right)$

\#4 TS=lingzhi

\#3 TS=(ling zhi)

\#2 TS=reishi

\#1 TS=ganoderma*

\section{BIOSIS}

\#14 \#13 AND \#9 
\#13 \#12 OR \#11 OR \#10

$\# 12$ TS=(arrythmi ${ }^{\star}$ or endocardi ${ }^{\star}$ or angina or ischem ${ }^{\star}$ or ischaem $\left.{ }^{\star}\right)$

$\# 11$ TS=(vascul ${ }^{\star}$ or (sick SAME sinus) or tachycardi ${ }^{\star}$ or (ventricular SAME fibrillat ${ }^{\star}$ ) or (atrial SAME fibrillat $\left.{ }^{\star}\right)$ )

$\# 10$ TS $=\left(\right.$ heart ${ }^{\star}$ or myocard ${ }^{\star}$ or cardio* or cardia* $^{\star}$ or coronary ${ }^{\star}$ or pericard ${ }^{\star}$ )

\#9 \#8 OR \#7 OR \#6 OR \#5 OR \#4 OR \#3 OR \#2 OR \#1

\#8 TS=reishus

\#7 TS=mannentake

\#6 TS=(medicinal ${ }^{*}$ SAME mushroom*)

\#5 TS=(chinese ${ }^{\star}$ SAME mushroom ${ }^{\star}$ )

\#4 TS=lingzhi

\#3 TS=(ling zhi)

\#2 TS=reishi

\#1 TS=ganoderma*

Appendix 3. Content experts contacted when searching for potentially eligible studies

\begin{tabular}{|c|c|c|}
\hline Name & Contact method & $\begin{array}{l}\text { Responses from the } \\
\text { authors }\end{array}$ \\
\hline \multicolumn{3}{|c|}{ First time of contact for additional possible relative research (7 December 2010) } \\
\hline Zhou Shufeng (National University of Singapore) & Mail \& Email & None \\
\hline Gao Yihuai (Massey University in New Zealand) & Mail & None \\
\hline Wang Chenwen (National Chung Hsing University in Taiwan) & Mail & $\begin{array}{l}\text { Returned as "Un- } \\
\text { known" (14 April 2011) }\end{array}$ \\
\hline Yuan Chunsu (University of Chicago) & Email & None \\
\hline Ming Yongxie (Nanchuang University in China) & Email & None \\
\hline Eva Guillamon (Campus Universitario “Duques de Soria” in Spain) & Email & None \\
\hline Zhang Ying (Beijing Sport University in China) & Email & None \\
\hline Masao Hattori (Toyama Medical and Pharmaceutical University in Japan) & Mail & None \\
\hline Lee KH (Ilyang Pharmaceutical Company in Korea) & Email & None \\
\hline Lee SY (Oral Roberts University School of Medicine in USA) & Mail & None \\
\hline Yoshihisa Nakagawa (Tenri Hospital in Japan) & Mail \& Email & None \\
\hline Iris Benzie (Hong Kong Polytechnic University) & Email \& Fax & None \\
\hline Kagaya Y (Sakamoto Bio Farm in Japan) & Email & None \\
\hline
\end{tabular}

Second time of contact for further data extraction (10 March 2011)

\begin{tabular}{lcc}
\hline Zhou Shufeng (National University of Singapore) & Mail & None \\
\hline $\begin{array}{l}\text { Xu Huiheng (Divisions of Endocrinology and Metabolism, Taichung Veterans } \\
\text { General Hospital, Department of Life Science, National Chung Hsing Universi- } \\
\text { ty, Taiwan) }\end{array}$ & Mail & None \\
\hline
\end{tabular}

\section{Third time of contact for additional possible relative research (24 March 2011)}


(Continued)

Shanghai Medical University, Shanghai (Huiming Jin, Guoping Zhang, Xiang Mail \& Email None Cao, Ming Zhang)

\begin{tabular}{lll}
\hline Xuzhou Institute of Cardiovascular Diseases (Jianjun Long, Bingqian Luo) & Mail & None \\
\hline Wakan Shoyaku Botany Institute, Tokyo, Japan (Masao Mori, Zhong Wang) & Mail & $\begin{array}{l}\text { Returned as “insuffi- } \\
\text { cient information” (14 } \\
\text { April 2011) }\end{array}$ \\
\hline Huiming Chen (No.1 Affiliated Hospital of Nanjing Medical University) & Mail None \\
\hline Shiming Qian (Nanjin Chinese Traditional Medical College) & Mail & None \\
\hline $\begin{array}{l}\text { Jin Lan (Institute of Human Nutrition and Department of Biochemistry, Qing- } \\
\text { dao Medical College, Qingdao University) }\end{array}$ & Mail & None \\
\hline $\begin{array}{l}\text { Xihu Dai, Fuzhou General Hospital of Nanjing Military Region of the Peoples” } \\
\text { Liberation Army, Fuzhou }\end{array}$ & Mail & None \\
\hline $\begin{array}{l}\text { Jinxian Ye, Hospital of Fujian University of Traditional Chinese Medicine, } \\
\text { Fuzhou }\end{array}$ & Mail & None \\
\hline \begin{tabular}{l} 
Guoliang Chen, Shanghai Academy of Agricultural Sciences \\
\hline
\end{tabular}
\end{tabular}

\section{WHAT' S NEW}

\begin{tabular}{lll}
\hline Date & Event & Description \\
\hline 21 September 2021 & Review declared as stable & $\begin{array}{l}\text { The intervention in this review is of low priority for clinical prac- } \\
\text { tice in the majority of counties. Therefore, this review is not con- } \\
\text { sidered to be updated. }\end{array}$ \\
\hline
\end{tabular}

\section{H IST ORY}

Protocol first published: Issue 3, 2008

Review first published: Issue 2, 2015

\section{CONTRIBUTIONS OFAUTHORS}

Securing funding for review: DC, HK, AB

Conceiving and co-ordinating review: NK

Data management in RevMan: $\mathrm{FH}, \mathrm{HC}$

Designing review: NK, FH, DC, SG, HK, AB

Submission of protocol: NK

Undertaking searches: NK (HC Chinese databases)

Reviewing titles and abstracts NK, FH (HC Chinese databases)

Retrieval of articles: NK (HC Chinese studies)

Translation of Chinese studies: HC

Screening search results for inclusion: NK, FH (HC Chinese databases)

Data extraction: $\mathrm{FH}$ and $\mathrm{HC}$

Risk of bias assessment: NK, HC, FH

Data analysis: $\mathrm{FH}, \mathrm{NK}$ 
Checking data entry: NK

Writing the review: NK, FH

Guarantor and first author: NK

\section{DECLARATIONS OF INTEREST}

NK, DC, AB, FH and HK are authors of an included trial Klupp 2014

$\mathrm{HC}$ : nothing to declare

SG: nothing to declare

$\mathrm{AB}$ : nothing to declare

\section{SOURCES OF SUPPORT}

\section{Internal sources}

- National Institute of Complementary Medicine, Australia

\section{External sources}

- Cardiac Health Institute, Australia

\section{DIFFERENCES BETWEEN PROTOCOLANDREVIEW}

More recent references have been provided for the background. These are Capewell 2011 and WHO 2011.

The methodological assessment as per protocol was updated according to current Cochrane guidelines.

The primary outcome 'incidence rates of any of the above' as listed in the protocol was changed to 'prevalence of any of the above'.

The terms 'change in' that preceded outcome measures has been removed. This suggested change scores would be used but end-scores were used.

In addition to the screening process as per the protocol, one additional reviewer $(\mathrm{HC})$ evaluated Chinese language titles an abstracts.

Due to changes in institutional access and database availability, the following databases were not searched as planned:

- Blackwell synergy

- Australian Medical Index

- Expanded Academic

- UK National Research Register

- Allied and Complementary Medicine Database (AMED)

- Centralized Information Service for Complementary Medicine (CISCOM)

- Traditional Chinese Medical Literature Analysis and Retrieval System (TCMLARS)

- Chinese Dissertation Database (CDDB)

- Chinese Academic Conference Papers (CACP)

- China Medical Academic Conference (CMAC)

- System for Information on Grey Literature in Europe (SIGLE)

In addition to databases listed in the protocol, the following databases were searched for Chinese language publications:

- China Network Knowledge Infrastruction (CNKI)

- VIP database.

In the protocol, it was stated that Ganoderma lucidum must be the only intervention. This was deemed too restrictive and was modified to allow for a lesser secondary constituent. The protocol was changed to "G lucidum is frequently combined with a second ingredient aimed to increase potency. Trials evaluating a combined formulation were included if there was only one additional ingredient and $G$ lucidum represented at least $75 \%$ of constituent weight."

Outcome measures were converted to metric values where possible e.g. $\mathrm{mg} / \mathrm{dL}$ was converted to $\mathrm{mmol} / \mathrm{L}$. 


\section{N D EX TERMS}

\section{Medical Subject Headings (MeSH)}

Blood Glucose [metabolism]; Body Mass Index; Cardiovascular Diseases [*prevention \& control]; Cholesterol [blood]; Diabetes Mellitus, Type 2 [blood] [ ${ }^{\star}$ therapy]; Drugs, Chinese Herbal [therapeutic use]; Glycated Hemoglobin A [analogs \& derivatives] [metabolism]; Randomized Controlled Trials as Topic; *Reishi; Risk Factors

\section{MeSH check words}

Humans 